\title{
Variabilidade decorativa na cerâmica paulista colonial: influências e resistências
}

Marcelo Manfrini*

MANFRINI, M. Variabilidade decorativa na cerâmica paulista colonial: influências e resistências. R. Museu Arq. Etn. 37: 178-203, 2021.

Resumo: As louças de barro produzidas e distribuídas na cidade de São Paulo durante os primeiros séculos de sua fundação apresentam uma grande variabilidade de motivos decorativos que exploravam múltiplas variantes de técnicas incisas, entalhadas, escovadas, digitadas e aplicadas. Tais técnicas podem ser relacionadas a estilos já encontrados em tradições indígenas e/ou afrodescendentes, que viriam a ser afetadas pelos efeitos da colonização europeia. Esses estilos decorativos vêm sendo frequentemente associados a morfologias que não são tipicamente observadas nessas mesmas tradições, e sim em produções europeias como xícaras, jarros e frigideiras. Com isso, pode-se observar que há uma amalgamação cultural fruto de processos de domínio e resistência. Pesquisas arqueológicas em contextos de Contato e da Diáspora frequentemente associam o uso de determinados estilos decorativos como formas de resistência e persistência cultural ante o domínio colonial europeu. Dessa forma, buscamos discutir os motivos decorativos identificados nos sítios arqueológicos Pinheiros 2, Casa do Bandeirante e Casa Bandeirista do Itaim Bibi, e procurar possíveis comparações com decorações indígenas ou afrodescendentes que possam nos oferecer dicas acerca das relações de poder na sociedade paulista e de como a persistência cultural pode ser observada na cerâmica local.

Palavras-chave: Arqueologia histórica; Cerâmica local/regional; Decorações; Arqueologia paulista.

\section{Introdução}

\footnotetext{
noção bastante difundida durante

Adécadas e que remontam a historiadores como Celso Furtado (2000) e Caio Prado Júnior (1969) acerca dos anos de fundação de São Paulo sempre foi de uma cidade pouco povoada, atrasada e com pouquíssima riqueza cultural, apenas se tornando relevante historicamente durante o período cafeeiro, entre os séculos XVIII

*Mestrando no Museu de Arqueologia e Etnologia da Universidade de São Paulo (MAE-USP). <marcelo.manfrini@usp.br>
}

e XX. Contudo, em tempos mais recentes, arqueólogos e historiadores vêm revisitando esses conceitos e mostrando um outro lado para essa cidade nos seus primeiros dois séculos, um lado mais economicamente ativo, socialmente diverso, e globalmente conectado (Andreatta 1986; Blaj 2002; Borrego 2010; Carrara 2014; Kok 2009; Monteiro 1995; Munsberg 2018; Petrone 1995; Reis Filho 2004; Souza 2013; Vilardaga 2011, 2017; Zanettini 2005).

Uma parte importante dessa revisão histórico-arqueológica é realmente a de pensar São Paulo enquanto uma grande 
amalgamação cultural, promovida pelo contato e pela convivência (muitas vezes forçada) entre europeus, indígenas e africanos. Mesmo em posições subalternas, a cultura material indígena e africana agiu de forma a se misturar com a produção europeia, formando novos e variados padrões decorativos. Entender essa variabilidade decorativa é fundamental para a compreensão das dinâmicas de poderes locais, além de enaltecer a resistência cultural empreendida por essas camadas subalternas mediante opressões coloniais, distanciandonos de conceitos como "acomodação cultural" (Agnolin 2007) ou “aculturação”. Esses conceitos nos afastam da agência que esses povos possuíam em relação à sua própria produção cerâmica, e levam ao entendimento de que processos de contato cultural são unilaterais, com os povos subalternos se incorporando à cultura do colonizador. Os processos de assimilação cultural são complexos, e são vias de mão dupla que envolvem camadas de processos de perda, poder e produção, que afetam tanto o colonizador quanto o colonizado (Arroyo 2016; Ortiz 1991; Sallum 2018; Wilson \& Rogers 1993).

Dessa forma, o objetivo central deste artigo será o de abordar a análise das decorações presentes em três sítios arqueológicos da cidade de São Paulo (o sítio Pinheiros 2; o sítio Casa do Bandeirante; e o sítio Casa Bandeirista do Itaim Bibi (Figura 1), e promover comparações entre a produção encontrada nesses locais e a produção encontrada em sítios europeus, sítios indígenas e afrodescendentes.

\section{Os sítios abordados}

O sítio Pinheiros 2 (UTM 23L 326727 7392356 - WGS84) foi escavado pela Zanettini Arqueologia entre os anos de 2010 e 2013. O contexto arqueológico do sítio em apreço é de uma olaria colonial, de onde foram exumados 9 fornos cerâmicos, 57.398 peças, dentre as quais 40.553 eram de cerâmica local/regional (Zanettini Arqueologia 2011a, 2012, 2013). O sítio recebeu 17 datações por termoluminescência (TL), que, em sua maioria, apontam para fins do século XVI até meados do século XVII.
A primeira pesquisa arqueológica desenvolvida na Casa Bandeirista do Itaim Bibi (UTM 23L 3283907390558 - WGS84) ocorreu entre junho e setembro de 1988 e foi coordenada pela arqueóloga Profa. $\mathrm{Dr}^{\mathrm{a}}$. Margarida Davina Andreatta, do Museu Paulista da Universidade de São Paulo (MP-USP). Essa pesquisa teve como um dos objetivos principais fornecer subsídios para as obras de restauro do bem tombado. Os objetivos da Profa. Dra. Andreatta, à época, não visavam exclusivamente atender às obras de restauro, mas ao entendimento do cotidiano da casa bandeirista desde a sua mais remota ocupação até meados do século XIX (Souza 2013). Assim, além das atividades de limpeza de entulho do interior da casa, foram abertas quatro trincheiras e realizadas múltiplas decapagens, gerando registros gráficos atualmente arquivados no MP-USP e o acervo de peças sob a salvaguarda do Departamento de Patrimônio Histórico (DPH). Somente em 2009, quando o terreno sofreu ações por parte de um empreendedor, que impactaram de modo irreversível o patrimônio arqueológico em apreço, é que novas pesquisas foram realizadas.

O conjunto cerâmico que está sendo considerado para o presente artigo é os das etapas entre 2009-2011, já que o material recebeu datações absolutas por TL e, de acordo com os relatórios existentes, existem áreas que podem ser associadas diretamente aos séculos XVI e XVII (Zanettini Arqueologia 2009, 2011b). Essas etapas geraram um acervo de 35.602 peças, sendo que 2.577 delas eram de fragmentos de cerâmica local/regional.

Em um projeto conjunto do Museu de Arqueologia e Etnologia da Universidade de São Paulo (MAE-USP) com o DPH, a Casa do Bandeirante (UTM 23L 325506 7393312) recebeu suas primeiras escavações em dezembro de 2012, que teriam continuidade em 2013. O sítio foi escavado com uma premissa de sítioescola, com a coordenação do campo sendo feita pelo Prof. Dr. Astolfo Araujo (MAE-USP) e pela Dra. Paula Nishida (DPH). Apesar da Casa atualmente ser reflexo de uma restauração ocorrida em 1955, a habitação existe naquela localização desde meados do século XVIII 
Variabilidade decorativa na cerâmica paulista colonial: influências e resistências

R. Museu Arq. Etn., 37: 178-203, 2021.

(Afonso dos Santos 2016; Mayumi 2008; Pacce 1980). Contudo, a ocupação no local pode datar de época ainda mais antiga. A Casa do Bandeirante é parte integrante da história do Butantã, cujos primórdios remontam a 1566 , ano em que foi concedida uma sesmaria a Jorge Moreira e Garcia Rodrigues. Há um registro em 1602 que documenta a propriedade como pertencente a Afonso Sardinha, com o nome Ubatatá, termo tupi para "terra dura". Contudo, tais documentos não são absolutamente confiáveis, já que suas terminologias vagas acabam por considerar terras em que hoje estão a Cidade Universitária e o Instituto Butantã, não a Casa do Bandeirante em si (Mayumi 2008; Pacce 1980).

$\mathrm{O}$ acervo da Casa do Bandeirante foi organizado de uma maneira diferente dos dois anteriores, de modo que sua metodologia de contagem também é distinta. Durante a escavação, todas as peças que não foram exumadas na peneira receberam plotagem via Estação Total (Taqueómetro) e assim receberam pontos X, Y e Z. Contudo, as peças que saíram nas peneiras não receberam o mesmo tratamento, assim não passando por um processo de curadoria. Para efeitos estatísticos desta pesquisa, optamos por apenas considerar as peças curadas, que totalizavam em 4.038 números individuais, aos quais 2.531 eram de fragmentos de cerâmica local/regional.

Tais sítios foram escolhidos por três motivos: (1) era preciso haver uma distinção entre centro produtor de cerâmica (Pinheiros 2) e locais de ocupação doméstica (Casa do Bandeirante e Casa Bandeirista do Itaim) para assim, talvez, poder estabelecer alguma relação entre produção e distribuição; (2) tais sítios também possuíam uma proximidade geográfica significativa, como pode ser visto na Figura 1 , especialmente antes da retificação do Rio Pinheiros, que colocava a Casa do Bandeirante na mesma margem do rio que os outros dois; (3) as datações de Pinheiros 2 e da Casa Bandeirista do Itaim apontam para uma possivel contemporaneidade entre ambos. Os registros históricos da Casa do Bandeirante também podem servir de indicativo para que esse sítio também seja de período similar aos outros dois.

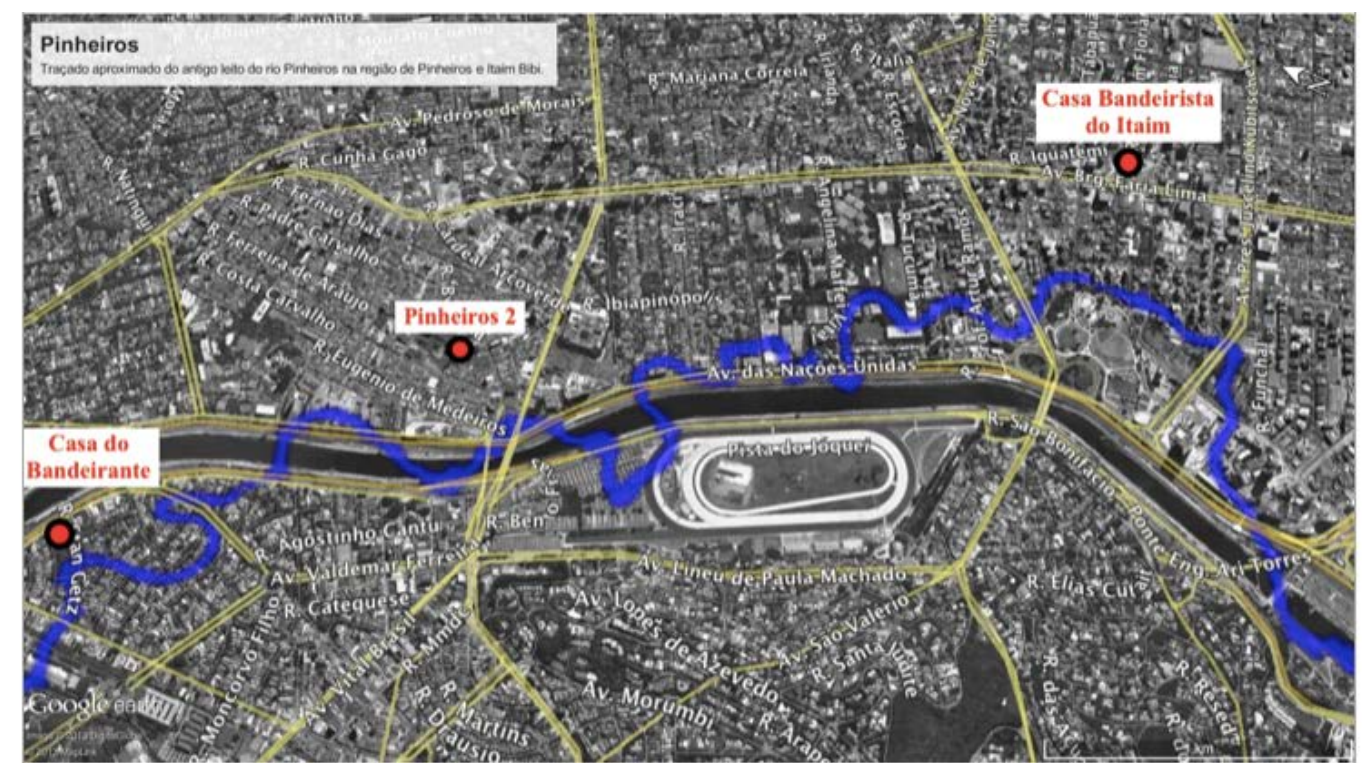

Fig. 1. Os três sítios abordados no presente artigo em relação à cidade de São Paulo e o traçado original do Rio Pinheiros.

Fonte: Kayo (2013). 
Contudo, mostra-se necessário compreender que a produção cerâmica encontrada na olaria do sítio Pinheiros 2, apesar de possuir uma mão de obra subalterna, com traços decorativos e produtivos de artesãos escravizados ou aldeados, é uma produção inserida dentro de uma lógica comercial regida pela população livre, não sendo assim, uma produção por e para escravos (Agostini 2010; Souza 2013).

\section{Metodologia}

Ao trabalharmos com esses sítios foi perceptível que existia uma quantidade de fragmentos incompativel com o tempo disponível para análise. Era necessário criar um recorte de modo a diminuir o universo amostral, mas, ainda sim, exibir uma amostra grande o suficiente para ser relevante. Dessa forma, o recorte se deu de maneiras similares (porém não idênticas) em todos os sítios. A característica base que servia para todos era de que fragmentos cerâmicos de corpo/parede - e sem decoração - menores que $5 \mathrm{~cm}$ não seriam analisados. Contudo, ainda assim era necessário adaptar alguns recortes para cada sítio. No caso de Pinheiros 2, optamos por apenas analisar os fragmentos advindos de intervenções que incidiam sobre ou imediatamente anexas às estruturas de queima e assim limitar a possibilidade de cerâmicas externas à produção da própria olaria. No caso da Casa Bandeirista do Itaim Bibi, optamos por focar nas áreas mais antigas do sítio e que já haviam sido datadas por TL. Dessa forma, poderíamos nos assegurar de que essas cerâmicas poderiam ser de período similar às encontradas no sítio Pinheiros 2. Por último, na Casa do Bandeirante, como não havia qualquer datação para nos guiar, optamos por fazer uma análise sistemática das peças que já possuíam curadoria, apenas utilizando o recorte base já mencionado anteriormente.

Sendo assim, analisamos um total de 5.409 fragmentos no sítio Pinheiros 2, o que representa $13,33 \%$ do total cerâmico do sítio; 727 fragmentos na Casa Bandeirista do Itaim Bibi, o que representa $28,21 \%$ do total cerâmico do sítio; e 1.138 números individuais da Casa do Bandeirante, o que representa um total de 44,96\% das cerâmicas curadas no sítio. Esse acervo gerou um total de 2.447 peças com decoração (1689 em Pinheiros 2; 319 na Casa Bandeirista do Itaim; e 439 na Casa do Bandeirante), e serão essas peças decoradas que serão abordadas de forma mais extensa neste artigo.

\section{Resultados}

Após a análise desses acervos cerâmicos, obtivemos uma significativa variabilidade de motivos decorativos, fazendo combinações entre diferentes técnicas decorativas, além de combinações entre diversos estilos. Contudo, é possivel perceber que alguns apareciam de maneira mais recorrente (mesmo que em conjunto com outros minoritários). A seguir, elaboramos um catálogo (Quadro 1) com todos os motivos decorativos identificados ao longo da análise desses três sítios arqueológicos e, juntamente com esse catálogo, também é destacado com qual percentual cada um é observado dentro de cada universo amostral decorativo. Entretanto, é importante destacar que, por causa de nossa metodologia, este trabalho não é exaustivo, já que além do nosso recorte, outros motivos decorativos podem vir a ser encontrados em proveniências distintas dos sítios. Também se mostra importante destacar que algumas decorações (apesar de serem consideradas iguais) podem ter aparências diferentes, como losangos menores ou maiores (Figura 2), traços mais finos ou mais grossos, ou mesmo apliques mais bem feitos ou menos bem feitos. Essas pequenas variações (que podem ser atribuídas a características individuais de cada artesão) foram desconsideradas para assim poderem ser agrupadas em motivos iguais. Porém, dependendo do olhar do pesquisador que possa vir a analisar estes sísios futuramente, mais variações podem vir a ser destacadas. 
Variabilidade decorativa na cerâmica paulista colonial: influências e resistências

R. Museu Arq. Etn., 37: 178-203, 2021.

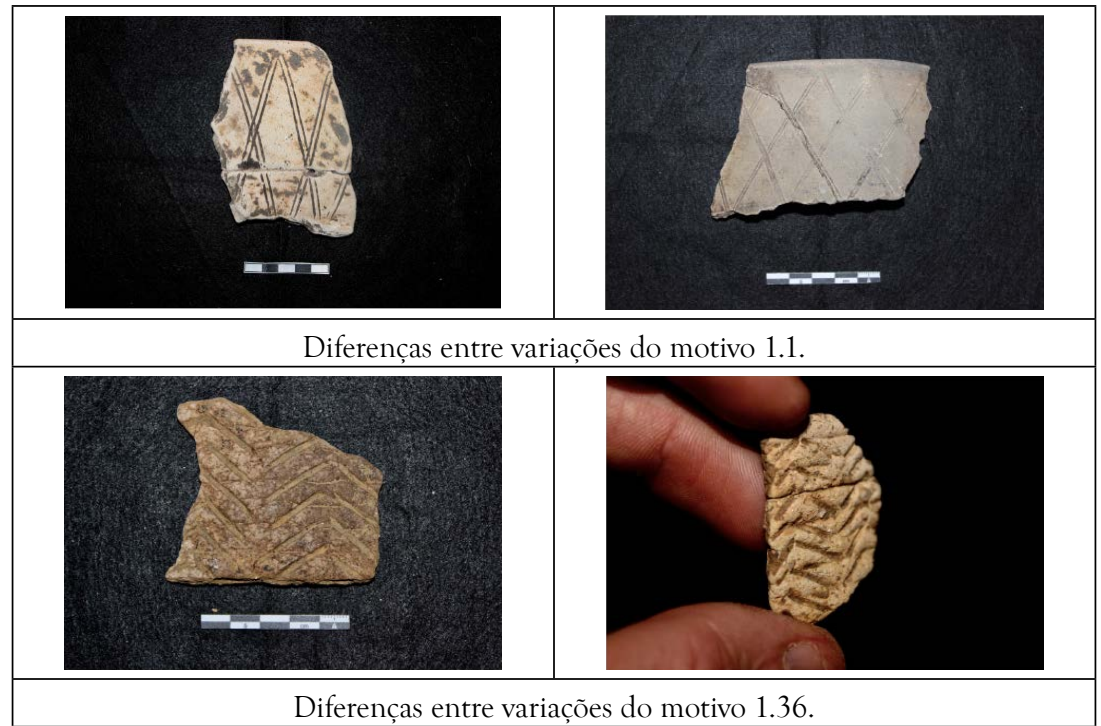

Fig. 2. Singularidade artesanal.

Fonte: elaborado pelo autor.

Para nos assistir na elaboração das categorias a seguir, fizemos uso de informações, nomes e croquis presentes em Zanettini Arqueologia (2012), Munsberg (2018) e Symanski (2010).
Porém, mesmo estes se mostraram insuficientes diante da quantidade de motivos identificados. Dessa forma, ainda foi necessária a criação de diversos croquis e nomes para diversas variações.

\begin{tabular}{|c|c|c|c|}
\hline Descrição da Decoração & Croqui & Imagem da Decoração & Porcentagem em cada sítio \\
\hline \multicolumn{4}{|l|}{ Incisões } \\
\hline $\begin{array}{l}\text { 1.1: Losangular simples } \\
\text { ou duplo }\end{array}$ & & & $\begin{array}{l}\text { - Pinheiros 2: 25,49\% } \\
\text { - Casa do Bandeirante: } 47,70 \% \\
\text { - Casa Bandeirista do Itaim } \\
\text { Bibi: } 27,59 \%\end{array}$ \\
\hline 1.2: Curvilíneo simples & & & $\begin{array}{l}\text { - Pinheiros 2: 5,91\% } \\
\text { - Casa do Bandeirante: 2,53\% } \\
\text { - Casa Bandeirista do Itaim } \\
\text { Bibi: } 0 \%\end{array}$ \\
\hline 1.3: Curvilíneo duplo & & & $\begin{array}{l}\text { - Pinheiros 2: 8,83\% } \\
\text { - Casa do Bandeirante: 3,23\% } \\
\text { - Casa Bandeirista do Itaim } \\
\text { Bibi: } 3,76 \%\end{array}$ \\
\hline
\end{tabular}




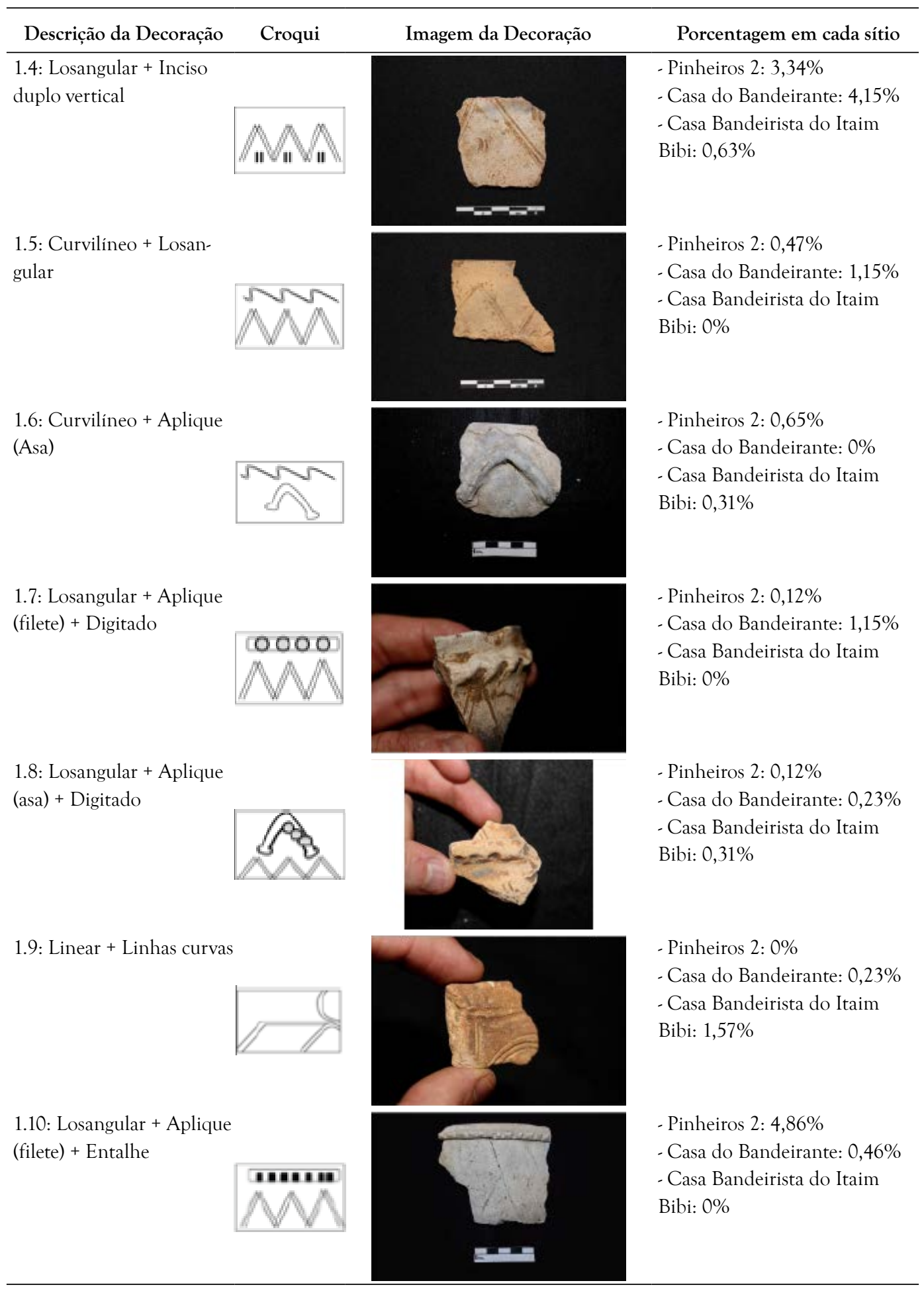


Variabilidade decorativa na cerâmica paulista colonial: influências e resistências

R. Museu Arq. Etn., 37: 178-203, 2021.

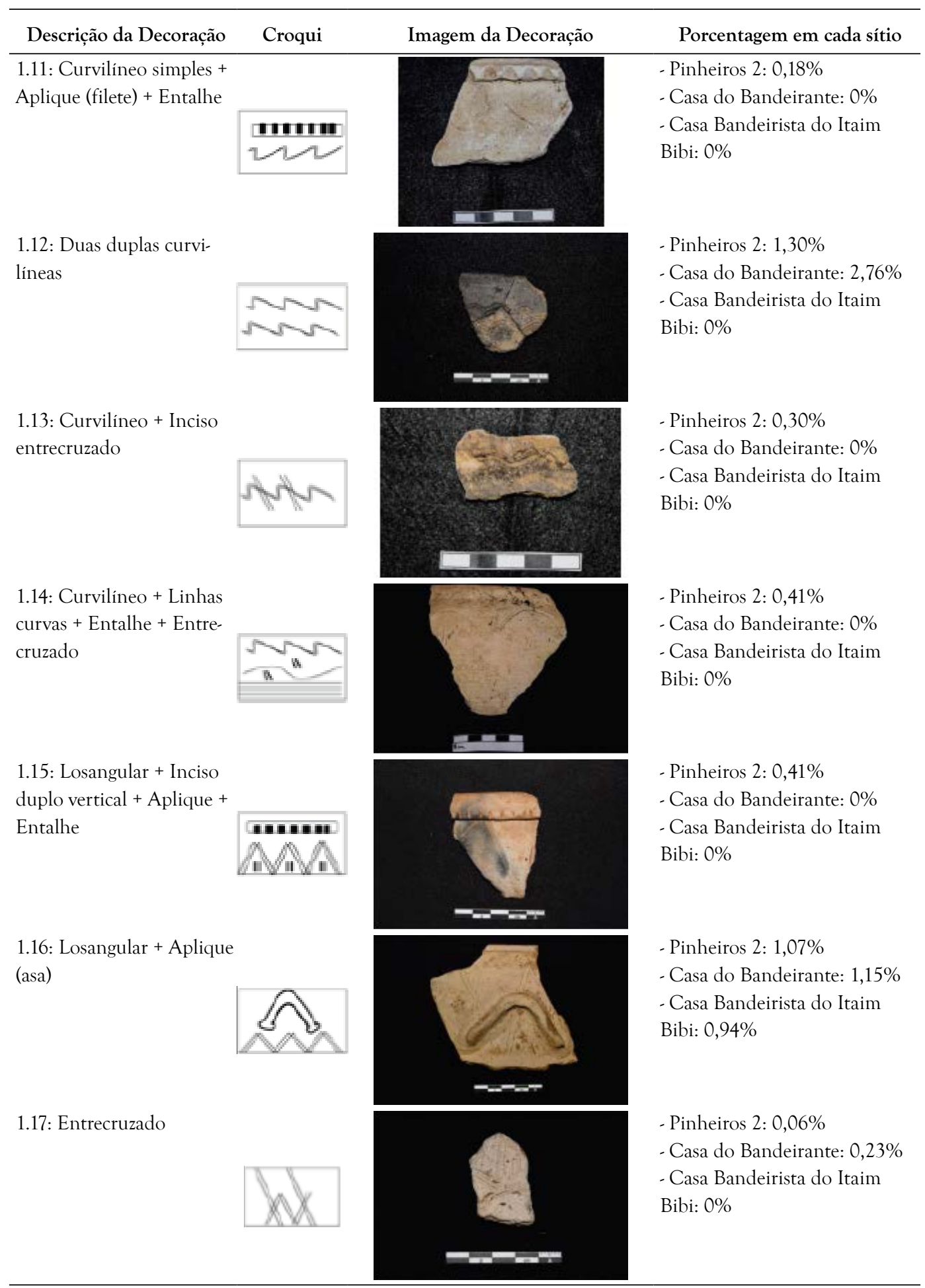




\begin{tabular}{llll}
\hline \multicolumn{1}{c}{ Descrição da Decoração } & Croqui & Imagem da Decoração & \multicolumn{1}{c}{ Porcentagem em cada sítio } \\
\hline $\begin{array}{l}\text { 1.18: Curvilíneo + } \\
\text { Losangular + Inciso } \\
\text { duplo vertical }\end{array}$ & & - Pinheiros 2: $1,24 \%$ \\
& & - Casa do Bandeirante: $0,46 \%$ \\
& - Casa Bandeirista do Itaim \\
& &
\end{tabular}

1.19: Losangular + Inciso duplo vertical + Filete aplicado

1.20: Curvilíneo duplo + Aplique (asa)

1.21: Curvilíneo duplo + Aplique linear

1.22: Arco duplo + Linhas verticais
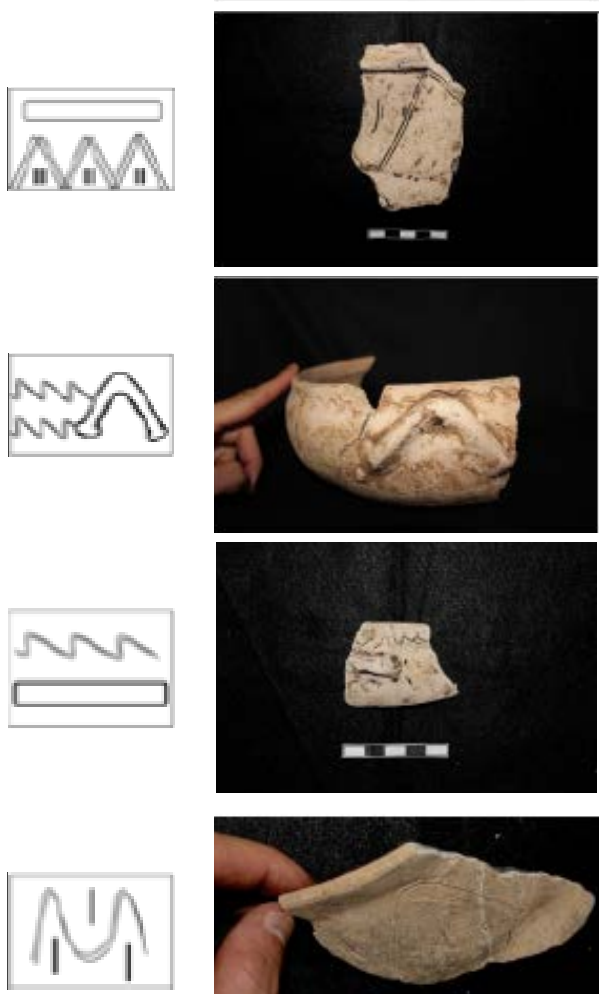

- Pinheiros 2: 0,24\%

- Casa do Bandeirante: 0\%

- Casa Bandeirista do Itaim

Bibi: 0\%
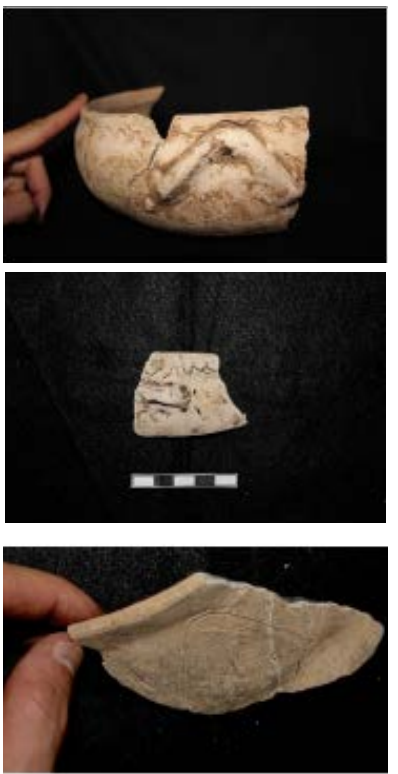

1.23: Losangular duplo + Aplique circular com inciso (cosmograma)

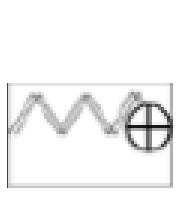

1.24: Arco duplo + Curvilíneo duplo + Linhas duplas em vertical
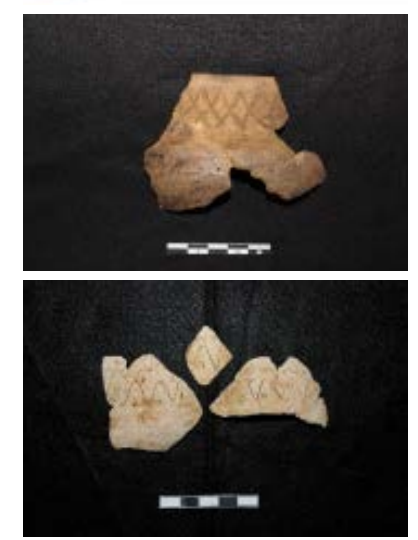

- Pinheiros 2: 0,36\%

- Casa do Bandeirante: 0\% - Casa Bandeirista do Itaim Bibi: 0\%

- Pinheiros 2: 0,36\%

- Casa do Bandeirante: 0\%

- Casa Bandeirista do Itaim Bibi: 0\%

- Pinheiros 2: 1,01\%

- Casa do Bandeirante: 0\% - Casa Bandeirista do Itaim Bibi: 0\%

- Pinheiros 2: 0,24\%

- Casa do Bandeirante: 0\% - Casa Bandeirista do Itaim Bibi: 0\%

- Pinheiros 2: 1,01\%

- Casa do Bandeirante: 0\% - Casa Bandeirista do Itaim Bibi: 0\% 
Variabilidade decorativa na cerâmica paulista colonial: influências e resistências

R. Museu Arq. Etn., 37: 178-203, 2021.

\begin{tabular}{lll}
\hline \multicolumn{1}{l}{ Descrição da Decoração } & Croqui & Imagem da Decoração \\
\hline $\begin{array}{l}\text { 1.25: Inciso não identifica- } \\
\text { do (INI) }\end{array}$ & \\
\end{tabular}

1.26: Dois frisos lineares + Incisos em "V"

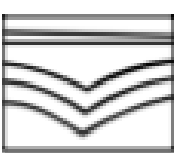

1.27: Incisos longos, rasos, difusos, que se sobrepõem
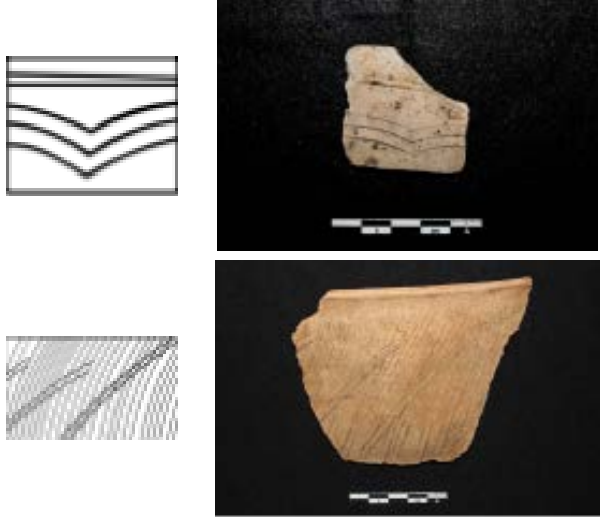

1.28: Arcos simples

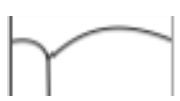

1.29: Incisos duplos curtos diagonais e paralelos

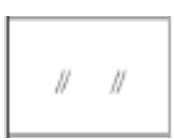

1.30: Incisos losangulares com múltiplas linhas

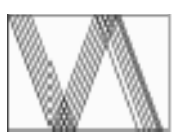

1.31: Rolete exposto + Incisos diagonais curtos linhas simples

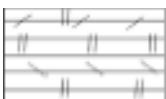

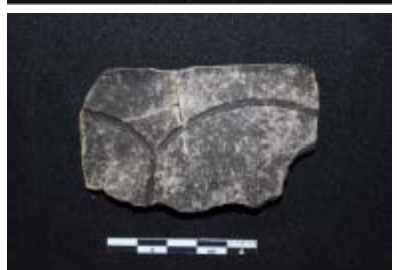
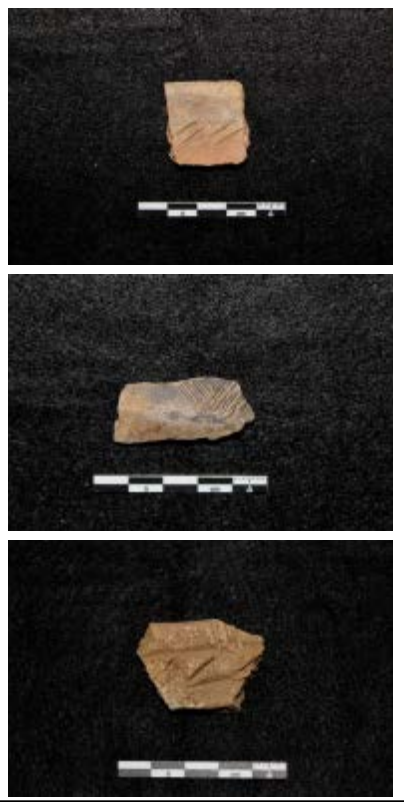

Porcentagem em cada sítio

- Pinheiros 2: 12,80\%

- Casa do Bandeirante: 11,06\%

- Casa Bandeirista do Itaim

Bibi: 8,46\%

- Pinheiros 2: 0,06\%

- Casa do Bandeirante: 0\%

- Casa Bandeirista do Itaim

Bibi: 0\%

- Pinheiros 2:0\%

- Casa do Bandeirante: 0,23\%

- Casa Bandeirista do Itaim

Bibi: 0\%

- Pinheiros 2: 0\%

- Casa do Bandeirante: 0,46\%

- Casa Bandeirista do Itaim

Bibi: 0\%

- Pinheiros 2:0\%

- Casa do Bandeirante: 0\%

- Casa Bandeirista do Itaim

Bibi: 0,31\%

- Pinheiros 2: 0\%

- Casa do Bandeirante: 0\%

- Casa Bandeirista do Itaim

Bibi: 0,31\%

- Pinheiros 2: 0\%

- Casa do Bandeirante: 0\%

- Casa Bandeirista do Itaim

Bibi: 0,94\% 


\begin{tabular}{l} 
Descrição da Decoração \\
\hline 1.32: Rolete exposto + \\
Losangos
\end{tabular}

paralelos

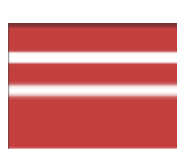

1.34: Incisos curtos e diagonais, paralelos no ombro do vasilhame

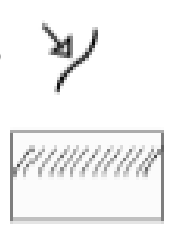

1.35: Incisos longos e paralelos em diagonal
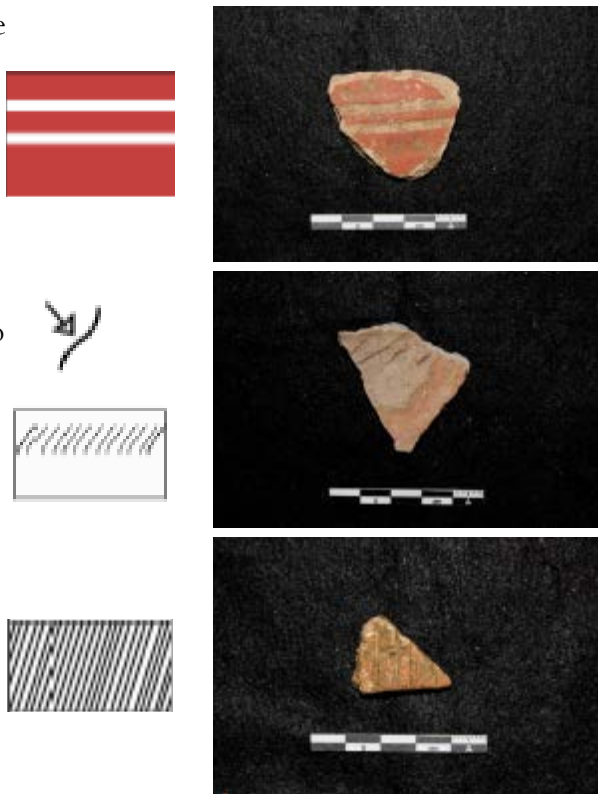

1.36: Espinha de peixe +

Rolete exposto
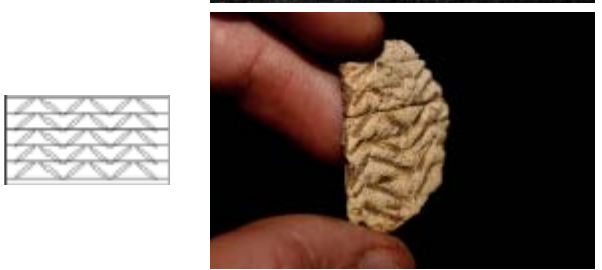

1.37: Friso simples junto ao lábio

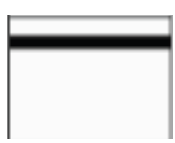

1.38: Losangular + Aplique com entalhes em trança
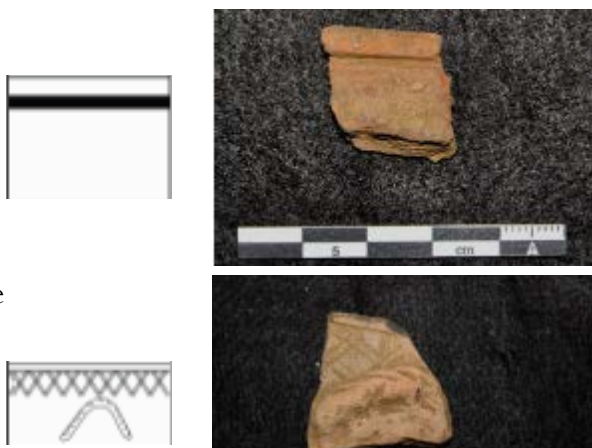

Porcentagem em cada sítio

- Pinheiros 2: 0\%

- Casa do Bandeirante: 0\%

- Casa Bandeirista do Itaim

Bibi: $1,88 \%$

- Pinheiros 2: 0\%

- Casa do Bandeirante: 0\%

- Casa Bandeirista do Itaim

Bibi: 0,31\%

- Pinheiros 2: 0\%

- Casa do Bandeirante: 0\% - Casa Bandeirista do Itaim Bibi: 0,63\%

- Pinheiros 2:0\%

- Casa do Bandeirante: 0\%

- Casa Bandeirista do Itaim

Bibi: 0,63\%

- Pinheiros 2:0\%

- Casa do Bandeirante: 0\%

- Casa Bandeirista do Itaim Bibi: 9,40\%

- Pinheiros 2:0\%

- Casa do Bandeirante: 0\% - Casa Bandeirista do Itaim Bibi: 0,63\%

- Pinheiros 2:0\%

- Casa do Bandeirante: 0\% - Casa Bandeirista do Itaim Bibi: 1,25\% 
Variabilidade decorativa na cerâmica paulista colonial: influências e resistências

R. Museu Arq. Etn., 37: 178-203, 2021.

Descrição da Decoração $\quad$ Croqui
1.39: Espinha de peixe +
Aplique com entalhes

triplos em oposição

Aplique em asa

\subsection{1: Penteado} angular + Digitado no ângulo da base
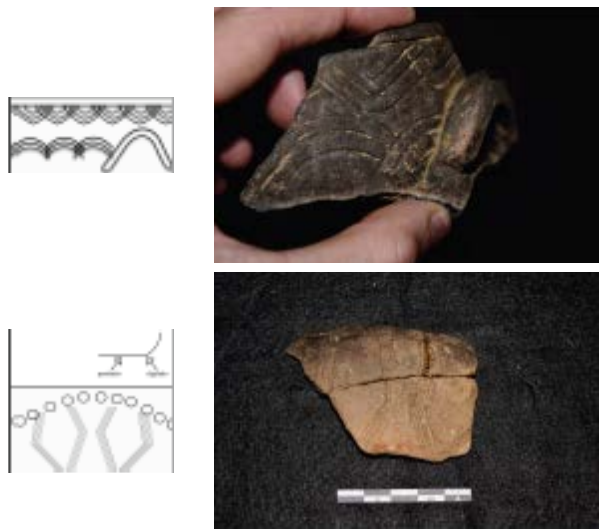

1.42: Rolete exposto + Linhas longas verticais duplas
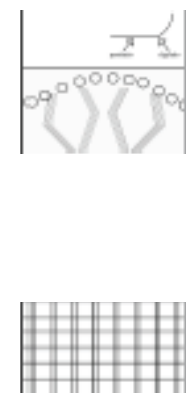

1.43: Penteado simples
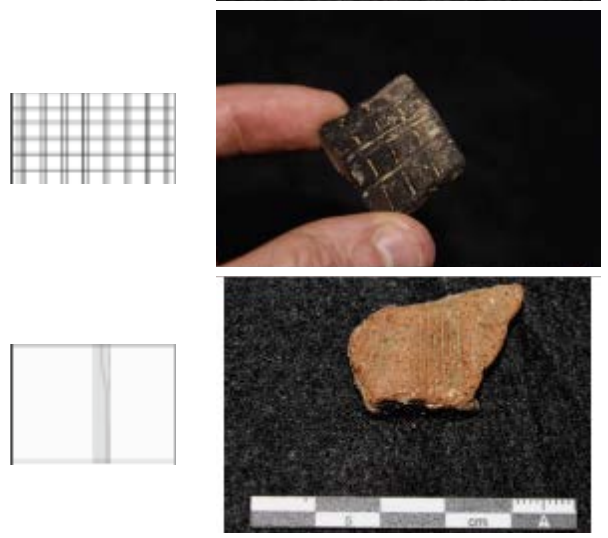

1.44: Incisos em "V"

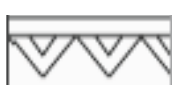

1.45: Incisos profundos, curtos, difusos e separados + Aplique digitado

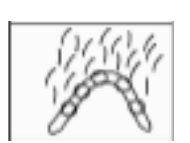

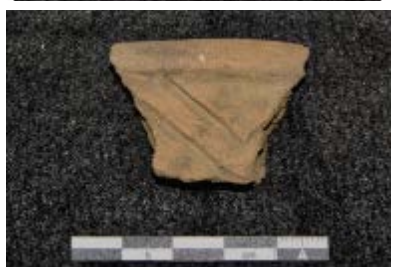

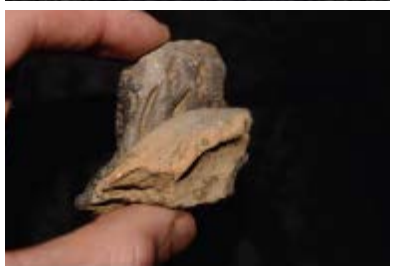

Porcentagem em cada sítio

- Pinheiros 2: 0\%

- Casa do Bandeirante: 0\%

- Casa Bandeirista do Itaim

Bibi: 0,94\%

- Pinheiros 2:0\%

- Casa do Bandeirante: 0\%

- Casa Bandeirista do Itaim

Bibi: 1,25\%

- Pinheiros 2:0\%

- Casa do Bandeirante: 0\%

- Casa Bandeirista do Itaim

Bibi: 1,25\%

- Pinheiros 2:0\%

- Casa do Bandeirante: 0\%

- Casa Bandeirista do Itaim

Bibi: 0,63\%

- Pinheiros 2:0\%

- Casa do Bandeirante: 0\%

- Casa Bandeirista do Itaim Bibi: 0,63\%

- Pinheiros 2:0\%

- Casa do Bandeirante: 0\%

- Casa Bandeirista do Itaim

Bibi: 0,94\%

- Pinheiros 2: 0\%

- Casa do Bandeirante: 0\%

- Casa Bandeirista do Itaim

Bibi: 0,63\% 


\begin{tabular}{|c|c|c|c|}
\hline Descrição da Decoração & Croqui & Imagem da Decoração & Porcentagem em cada sítio \\
\hline $\begin{array}{l}\text { 1.46: Curvilíneo } \\
\text { multidirecional }\end{array}$ & & & $\begin{array}{l}\text { - Pinheiros 2: 0\% } \\
\text { - Casa do Bandeirante: 0\% } \\
\text { - Casa Bandeirista do Itaim } \\
\text { Bibi: 0,31\% }\end{array}$ \\
\hline $\begin{array}{l}\text { 1.47: Rolete exposto + } \\
\text { Linhas longas verticais } \\
\text { sob linhas diagonais }\end{array}$ & & & $\begin{array}{l}\text { - Pinheiros 2: 0\% } \\
\text { - Casa do Bandeirante: 0\% } \\
\text { - Casa Bandeirista do Itaim } \\
\text { Bibi: 0,31\% }\end{array}$ \\
\hline $\begin{array}{l}\text { 1.48: Rolete exposto + } \\
\text { Penteado em espinha } \\
\text { de peixe }\end{array}$ & & & $\begin{array}{l}\text { - Pinheiros 2: 0\% } \\
\text { - Casa do Bandeirante: 0\% } \\
\text { - Casa Bandeirista do Itaim } \\
\text { Bibi: } 0,94 \%\end{array}$ \\
\hline $\begin{array}{l}\text { 1.49: Losangular }+ \\
\text { Incisos curtos, diagonais } \\
\text { e paralelos }\end{array}$ & & & $\begin{array}{l}\text { - Pinheiros 2: 0\% } \\
\text { - Casa do Bandeirante: 0\% } \\
\text { - Casa Bandeirista do Itaim } \\
\text { Bibi: } 0,31 \%\end{array}$ \\
\hline $\begin{array}{l}\text { 1.50: Curvilíneo + Losan- } \\
\text { gular + Inciso + Duplo } \\
\text { vertical + Aplique em asa }\end{array}$ & & & $\begin{array}{l}\text { - Pinheiros 2: 0\% } \\
\text { - Casa do Bandeirante: 0,46\% } \\
\text { - Casa Bandeirista do Itaim } \\
\text { Bibi: } 0 \%\end{array}$ \\
\hline
\end{tabular}

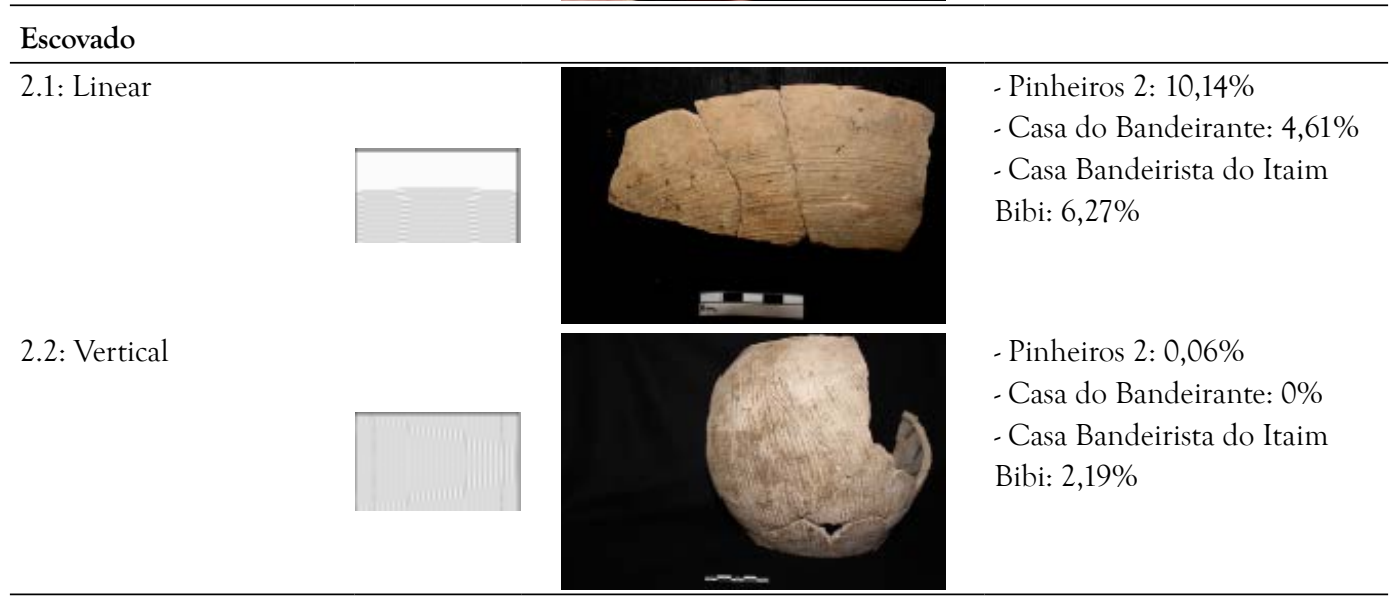


Variabilidade decorativa na cerâmica paulista colonial: influências e resistências R. Museu Arq. Etn., 37: 178-203, 2021.

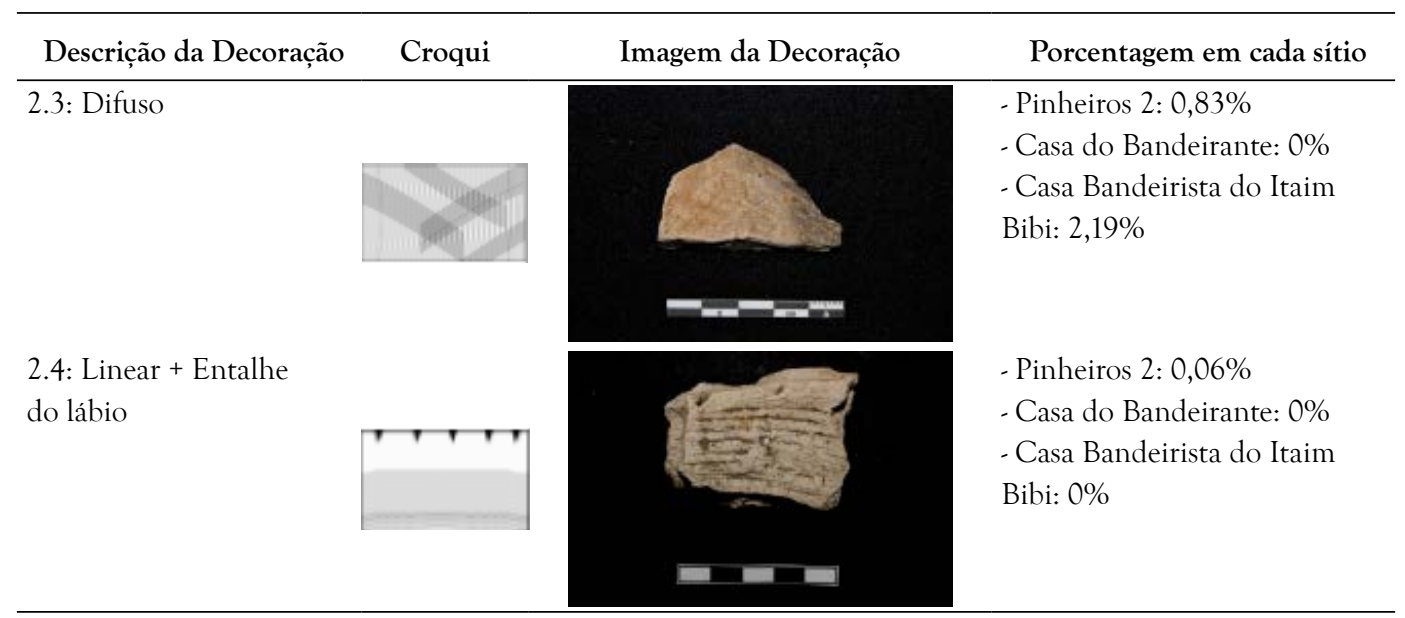

\section{Digitado}

3.1: No lábio

3.2: No ângulo da base

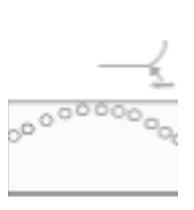

3.3: Rolete exposto +

Digitado

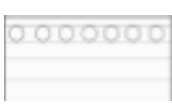

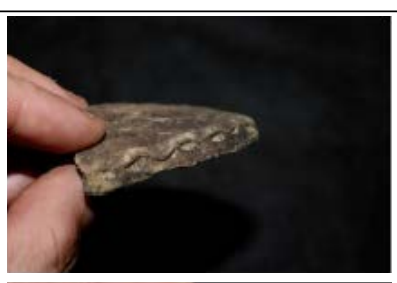
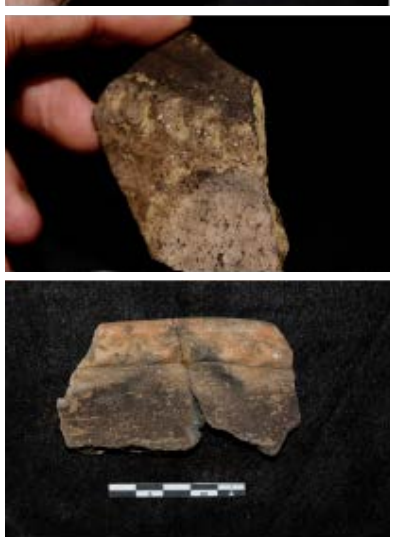

- Pinheiros 2: 0\%

- Casa do Bandeirante: 0\%

- Casa Bandeirista do Itaim

Bibi: 2,19\%

\section{Entalhado}

\begin{tabular}{ll}
\hline 4.1: No lábio & $\begin{array}{l}\text { - Pinheiros 2: } 0,47 \% \\
\text { - Casa do Bandeirante: } 0,92 \% \\
\text { - Casa Bandeirista do Itaim } \\
\text { Bibi: } 0,94 \%\end{array}$ \\
\hline
\end{tabular}




\begin{tabular}{llll}
\hline \multicolumn{1}{c}{ Descrição da Decoração } & Croqui & Imagem da Decoração & Porcentagem em cada sítio \\
\hline 4.2: Entalhes difusos & & $\begin{array}{l}\text { - Pinheiros 2: } 0,12 \% \\
\text { - Casa do Bandeirante: } 0 \% \\
\text { no corpo }\end{array}$ \\
&
\end{tabular}

\section{Aplicado}

5.1: Asa (linear)
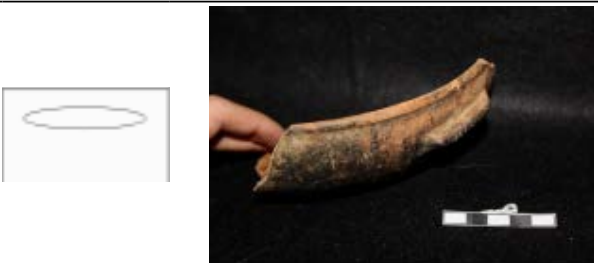

5.2: Asa (curva)
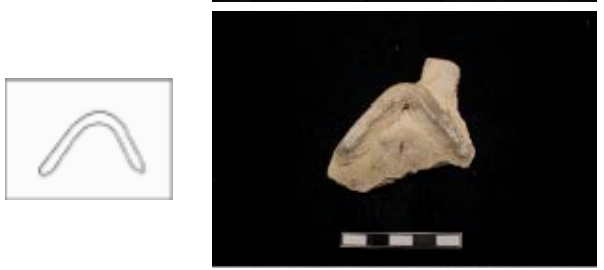

5.3: Alças e cabos

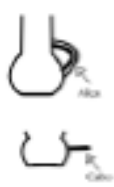

5.4: Filete aplicado

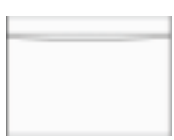

5.5: Filete aplicado + Entalhe

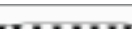

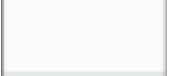

5.6: Filete (ou asa) +

Digitado

0000000
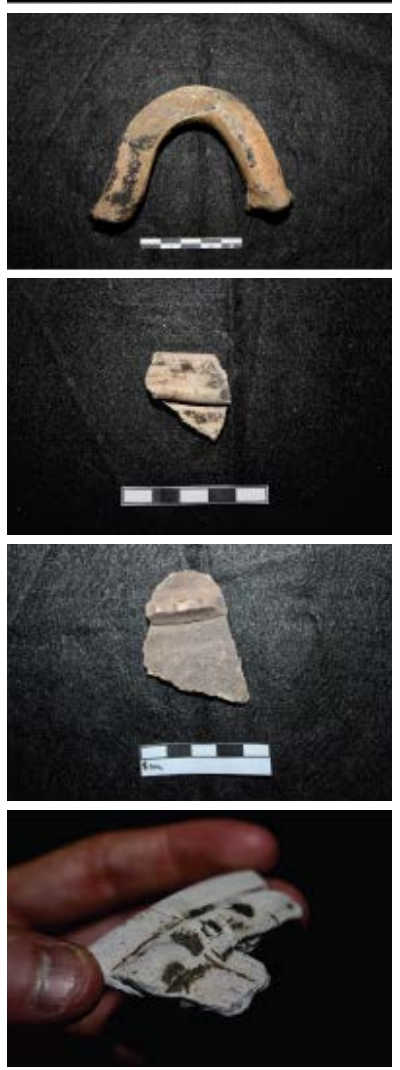

- Pinheiros 2: 7,47\%

- Casa do Bandeirante: 8,06\%

- Casa Bandeirista do Itaim

Bibi: $1,57 \%$

- Pinheiros 2: 0,47\%

- Casa do Bandeirante: 1,38\%

- Casa Bandeirista do Itaim

Bibi: 1,25\%

- Pinheiros 2: 0,47\%

- Casa do Bandeirante: 1,61\%

- Casa Bandeirista do Itaim

Bibi: $1,57 \%$

- Pinheiros 2: 0,24\%

- Casa do Bandeirante: 0\%

- Casa Bandeirista do Itaim

Bibi: 0\%

- Pinheiros 2: 5,99\%

- Casa do Bandeirante: 0\%

- Casa Bandeirista do Itaim

Bibi: 0,63\%

- Pinheiros 2: 0,12\%

- Casa do Bandeirante: 0\%

- Casa Bandeirista do Itaim

Bibi: 0\% 
Variabilidade decorativa na cerâmica paulista colonial: influências e resistências R. Museu Arq. Etn., 37: 178-203, 2021.

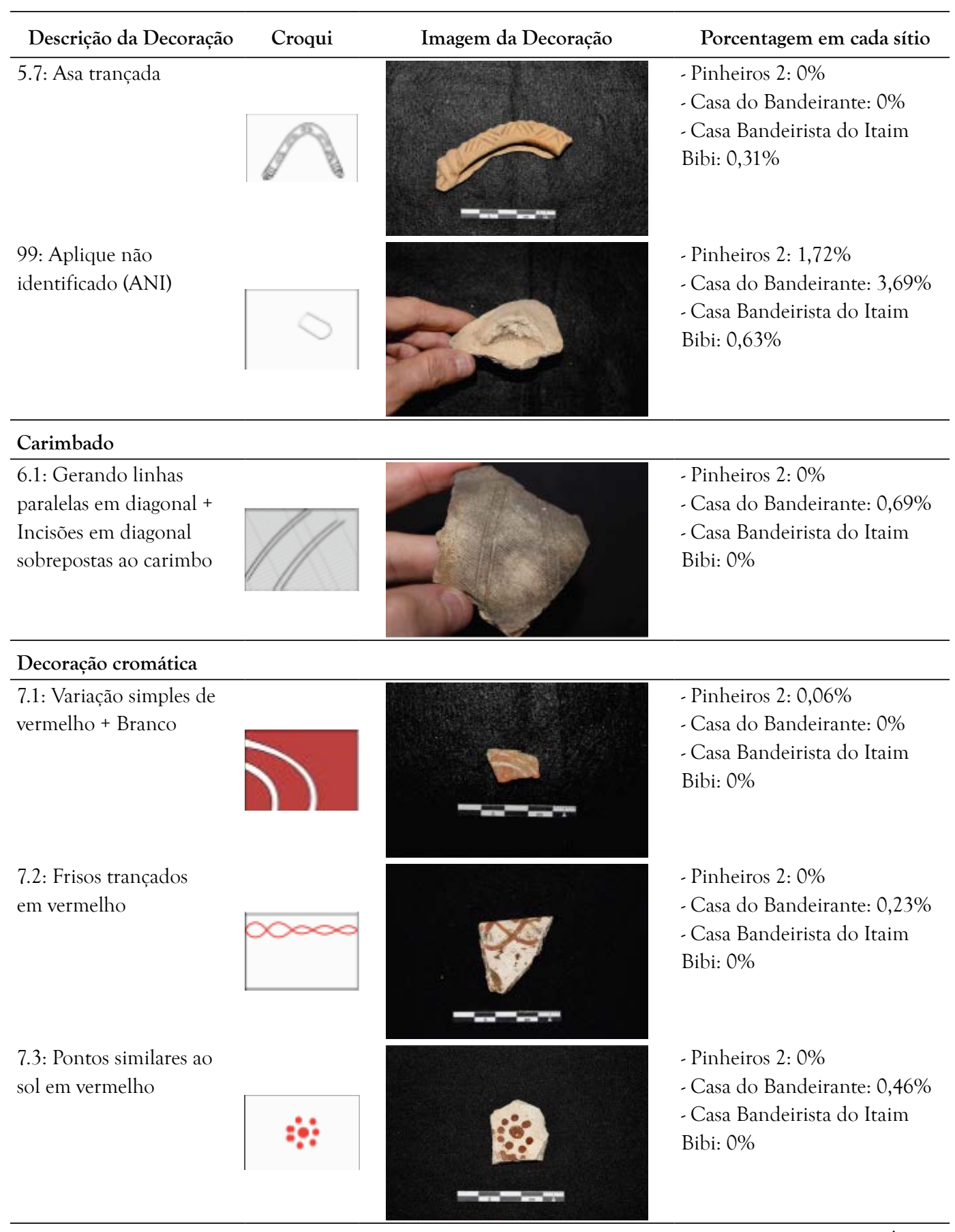




\begin{tabular}{llll}
\hline Descrição da Decoração & Croqui & Imagem da Decoração & Porcentagem em cada sítio \\
\hline $\begin{array}{l}\text { 7.4: Formatos em asterisco } \\
+ \text { Formatos circulares }\end{array}$ & $\begin{array}{l}\text { - Pinheiros 2: } 0 \% \\
\text { - Casa do Bandeirante: } 0 \% \\
\text { - Casa Bandeirista do Itaim } \\
\text { Bibi: } 0,31 \%\end{array}$ \\
\hline
\end{tabular}

\section{Roletada}

8.1: Rolete exposto simples
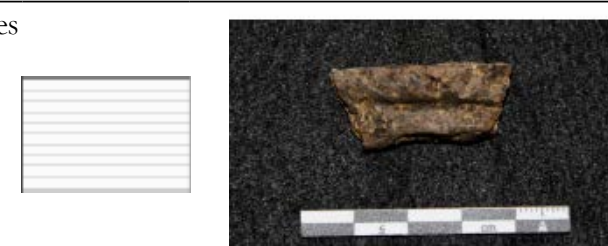

- Pinheiros 2:0\%

- Casa do Bandeirante: 0\%

- Casa Bandeirista do Itaim

Bibi: 1,25\%

\begin{tabular}{lll}
\hline Corrugado & \\
\hline 9.1: Corrugado simples & - Pinheiros 2: $0 \%$ \\
& & - Casa do Bandeirante: $0 \%$ \\
& & - Casa Bandeirista do Itaim \\
& Bibi: $0,31 \%$ \\
\hline
\end{tabular}

Quadro 1. Catálogo decorativo.

Fonte: elaborado pelo autor.

\section{Discussão}

Como pudemos observar no catálogo elaborado na seção anterior, foram identificadas diversas combinações entre motivos incisos losangulares e curvilíneos, além de usos de escovados, entalhes, apliques etc. Porém, quem estava produzindo essas decorações? Essas decorações não são tipicamente portuguesas, principalmente ao se tomar por base cerâmicas portuguesas entre os séculos XIII e XX (Barros et al. 2012; Cardoso \& Batalha 2017; Casimiro \& Barros 2012; Casimiro et al. 2018; Neoépica Arqueologia 2017), assim como não são tipicamente indígenas ou mesmo afrodescendentes. Contudo, características mescladas e similaridades produtivas podem ser observadas nas decorações presentes nesses sítios coloniais.
O uso do inciso losangular é comum entre comunidades indigenas e afrodescendentes. Na Figura 3, podemos observar alguns exemplos presentes em sítios indígenas do Mato Grosso, Mato Grosso do Sul e Espírito Santo. Já na Figura 4, observamos motivos losangulares em contextos afrodescendentes. Dessa mesma forma, o uso de decorações escovadas e o uso de engobo vermelho também aparecem de forma recorrente na cerâmica indígena (Figura 5).

Já o curvilíneo se mostra bastante comum na cerâmica portuguesa medieval e pósmedieval, além de ser observada em faianças e cerâmicas vidradas. Na Figura 6, podemos observar alguns desses exemplos. $\mathrm{O}$ uso do aplique com uma depressão central e digitado na extremidade também aparece em cerâmicas europeias, assim como o filete entalhado junto ao lábio (Figura 7). 
Variabilidade decorativa na cerâmica paulista colonial: influências e resistências R. Museu Arq. Etn., 37: 178-203, 2021.

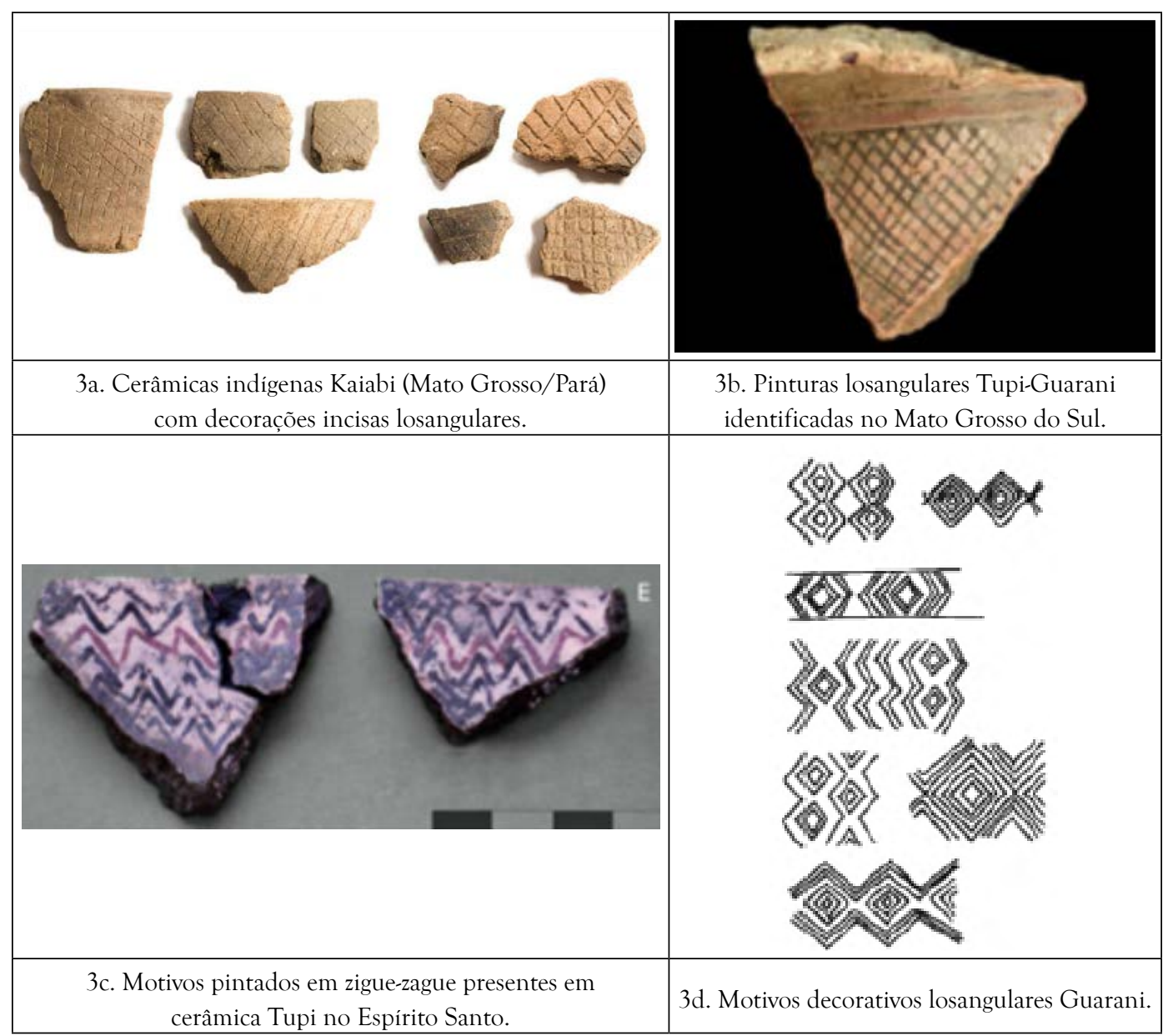

Fig. 3. Motivos losangulares entre tradições indígenas.

Fonte: 3a. Gaspar (2014); 3b. Kashimoto \& Martins (2019); 3c. Ribeiro \& Jácome (2014); 3d. Tocchetto (1996b).

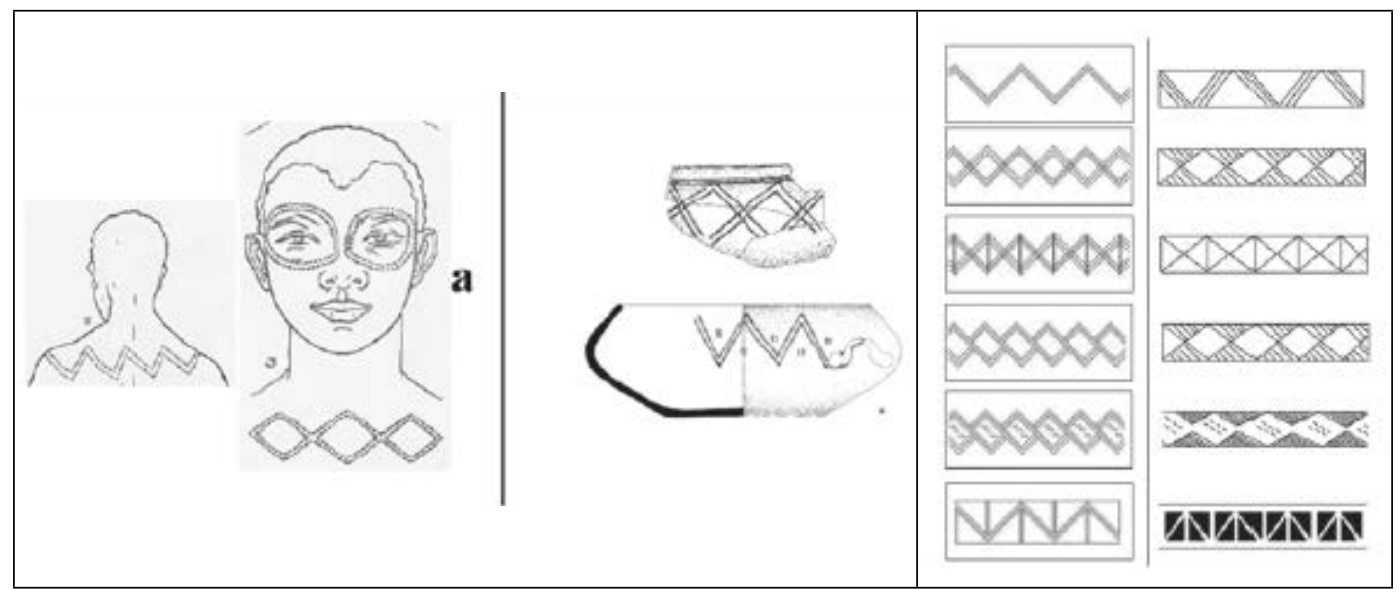

Fig. 4. Motivos losangulares em cerâmicas e escarificações corporais entre os Ovimbundu (África Central). Fonte: Symanski (2010). 


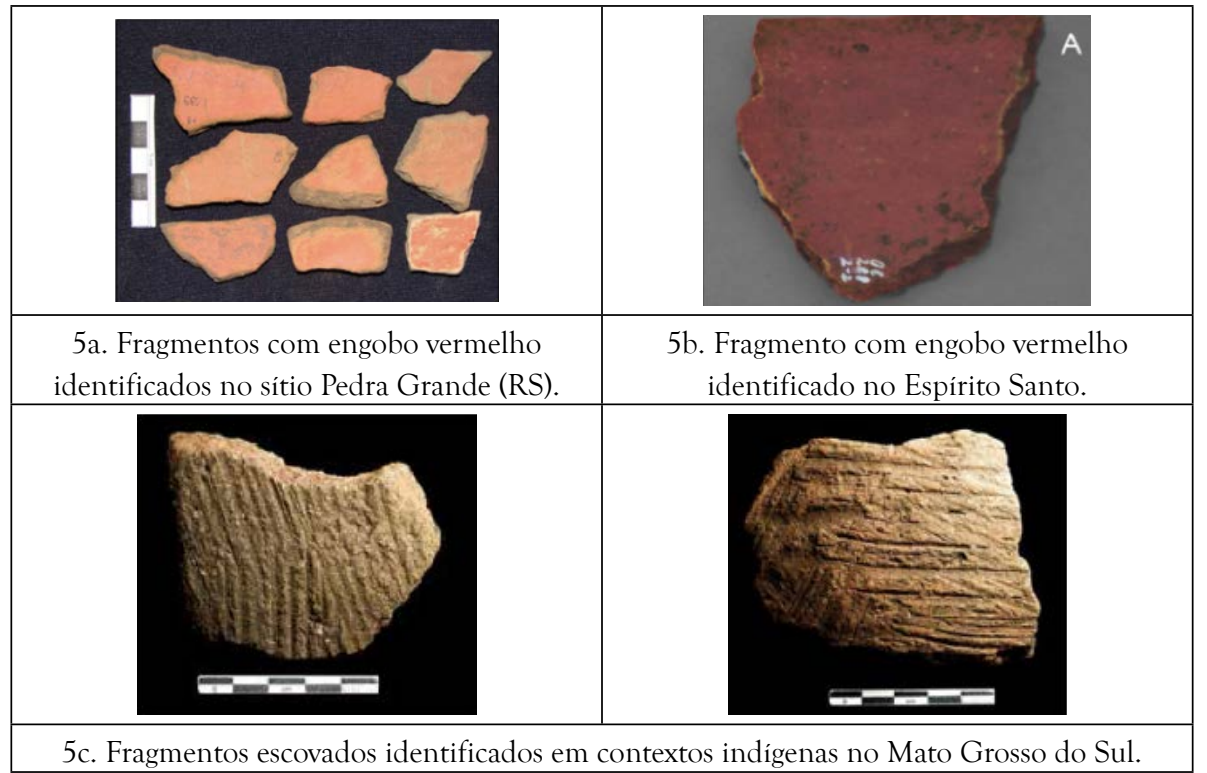

Fig. 5. Uso de engobo vermelho e decorações escovadas entre tradições indígenas.

Fonte: 5a. Zuse (2009); 5b. Ribeiro \& Jácome (2014); 5c. Kashimoto \& Martins (2019).

\begin{tabular}{|c|c|}
\hline 6a. Peça portuguesa com & 6b. Peça portuguesa com \\
\hline decoração incisa curvilínea. & decoraça incisa curvilínea. \\
\hline 6c. Fragmento de cerâmica portuguesa & 6d. Peça portuguesa com \\
\hline com decoração incisa curvilínea. & decoraça incisa curvilínea. \\
\hline 6e. Fragmentos de faianças portuguesas & 6f. Fragmento de cerâmica vidrada \\
\hline com motivos curvilíneos. & encontrada na Casa do Bandeirante. \\
\hline
\end{tabular}

Fig. 6. Uso do curvilíneo em Portugal.

Fonte: 6a. Casimiro et al. (2018); 6b. Neoépica Arqueologia (2017); 6c. Barros et al. (2012); 6d. Casimiro \& Barros (2012); 6e. Albuquerque (2001); 6f. Acervo do autor. 


\begin{tabular}{|l|l|}
\hline 3a. Cerâmicas indígenas Kaiabi (Mato Gros- \\
so/Pará) com decorações incisas losangulares.
\end{tabular}

Fig. 7. Apliques estilizados em Portugal vs. São Paulo.

Fonte: acervo do autor.

Decorações em "espinha de peixe" aparecem na cerâmica africana, assim como o aplique com incisos em cruz, atribuídos a comunidades Bakongo (Munsberg 2018; Symanski 2010).
O uso do rolete exposto, por outro lado, é recorrente na produção cerâmica africana, assim como na cerâmica encontrada em tradições indígenas brasileiras (Figura 8).

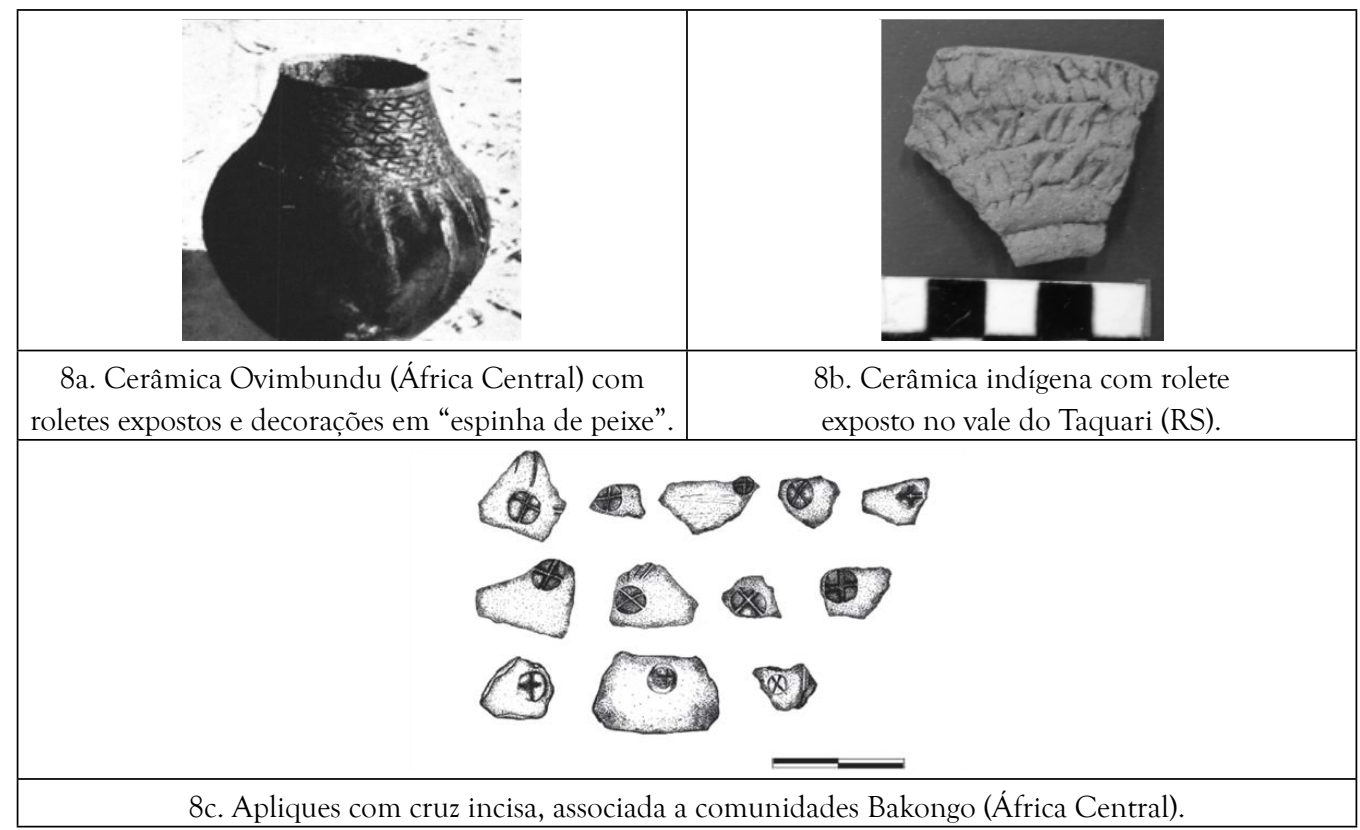

Fig. 8. Uso de motivos Bakongo, "espinha de peixe" e roletes expostos.

Fonte: 8a. Hauenstein (1964) apud Munsberg (2018); 8b. Machado, Schneider \& Shneider (2008); 8c. Symanski (2010). 
Tais combinações entre motivos indígenas, europeus e africanos na cerâmica de período colonial brasileira já foi trabalhada em artigos como Agostini (1998a), Brochado (1973), Dias Júnior (1988), Magalhães (2015), Moreira (2019), Sallum (2018), Souza (2013) Tocchetto (1996a), Zuse (2009) e neles a presença de motivos incisos, escovados e engobos é tida como característica dessas confluências e resistências culturais.

Entender a decoração como mais do que apenas "arte pela arte" (David, Sterner \& Gavua 1988) é bastante relevante para esta discussão. $\mathrm{O}$ trabalho presente nesses vasilhames cerâmicos representa mais do que somente um caráter estético, e sim um reforço de valores sociais. De acordo com David, Sterner \& Gavua (1988), os desenhos presentes da cerâmica eram canais que as sociedades tradicionais implantavam seus valores simbólicos nas horas individuais de alimentação. Essa forma de interpretação também é utilizada por Erig Lima (2012) e Hegmon (1992). Dessa forma, o indivíduo fazia uso desse recurso criativo e identitário para transmitir e mostrar seus valores pessoais. Souza (2013) ainda aborda a temática das decorações em contextos de diáspora africana, em que ele discute essa grande variabilidade de motivos decorativos e técnicas, além do modo ao qual os artesãos sobrepunham esses diferentes estilos sem invalidar os anteriores. Ele entende esse fenômeno como uma forma de sintese cultural em que o artesão faz uso dessa prática de modo a sobrepôr diferenças culturais e operar de modo a aceitar novas práticas decorativas. Em uma sociedade que pessoas das mais diferentes partes do globo eram forçadas a conviver em um ambiente hostil, essa forma de manutenção e reinvenção decorativa se torna uma parte importante do cotidiano criativo (Campos 2007; Mrozowski, Gould \& Pezzarossi 2015).

É importante ressaltar que os primeiros registros de populações africanas em solo paulistano só aparecem em 1612 (Taunay 2004), e a substituição sistemática de mão de obra indígena pela de negros escravizados só ocorre em meados do século XVIII. Dessa forma, por causa das datações absolutas presentes no sítio Pinheiros 2 e na Casa Bandeirista do Itaim $\mathrm{Bibi}$, a probabilidade de que os artesãos das cerâmicas exumadas sejam de origem africana é baixa, e as decorações devem ser mais facilmente associadas a contextos de mão de obra indígena (Lemos 2008; Monteiro 1995; Taunay 2004).

\section{Considerações finais}

Como foi possível observar ao longo deste artigo, os motivos decorativos encontrados no registro arqueológico proveniente dos três sítios arqueológicos aqui em análise apresentam uma variabilidade significativa. É importante ressaltar que esses padrões perduraram, sendo observados em sítios arqueológicos dos séculos XIX e XX (Agostini 1998a, 1998b, 2009, 2010, 2011; Sallum 2018; Souza \& Agostini 201). Em alguns casos, alguns motivos ainda podem ser observados atualmente, como é o caso da cestaria com motivos losangulares entre comunidades Guarani no Paraná e em comunidades Baniwa no extremo norte do país (Figura 9). Essa fusão cultural, mesmo que feita por meio de relações de poder desproporcionais, pode ser relacionada a uma cultura material mista em São Paulo, relaciona-se diretamente como uma forma de resistência desenvolvida pelos artesãos, criando uma forma de manter parte de suas identidades tradicionais (Agostini 1998b; Mrozowski, Gould \& Pezzarossi 2015; Sallum 2018; Wilson \& Rogers 1993).

A mudança drástica nas relações de poder entre colonizador e colonizado também foram fundamentais na interpretação da decoração cerâmica e se tornou necessário entender os processos cognitivos e culturais que estavam sendo impostos pelos colonizadores, assim como essas estratégias de resistência cultural que estavam sendo empreendidas pelos colonizados. Orser (1999: 94) definiu essa situação como "relações de poder verticais", já que presumiam algo intrínseco ao funcionamento capitalista: hierarquia. Dessa forma, apesar de a cerâmica ser produzida por mãos escravizadas, a cerâmica 
Variabilidade decorativa na cerâmica paulista colonial: influências e resistências R. Museu Arq. Etn., 37: 178-203, 2021.

se encontrava integrada a uma lógica mercantil voltada para um mercado de pessoas livres (Agostini 2010), permitindo uma combinação entre a criatividade e a inovação de seus artesãos a formatos e a morfologias ligadas a um mercado europeizado (Figura 10).

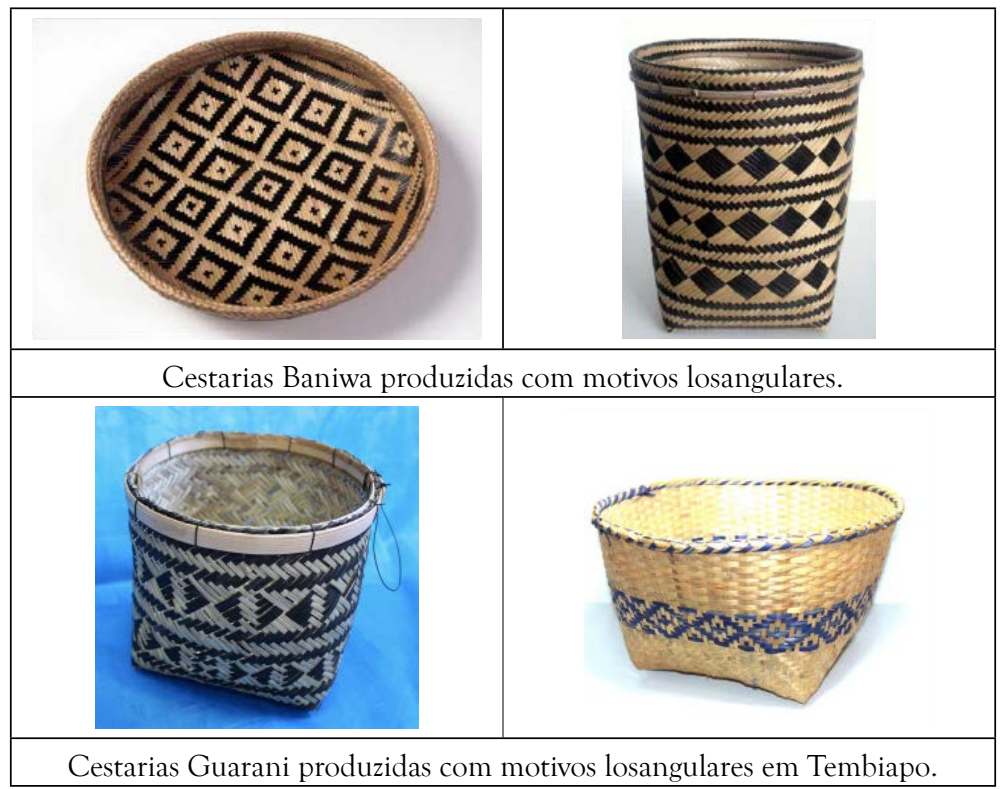

Fig. 9. Cestarias no século XXI.

Fonte: Acervo do Museu do Objeto Brasileiro.

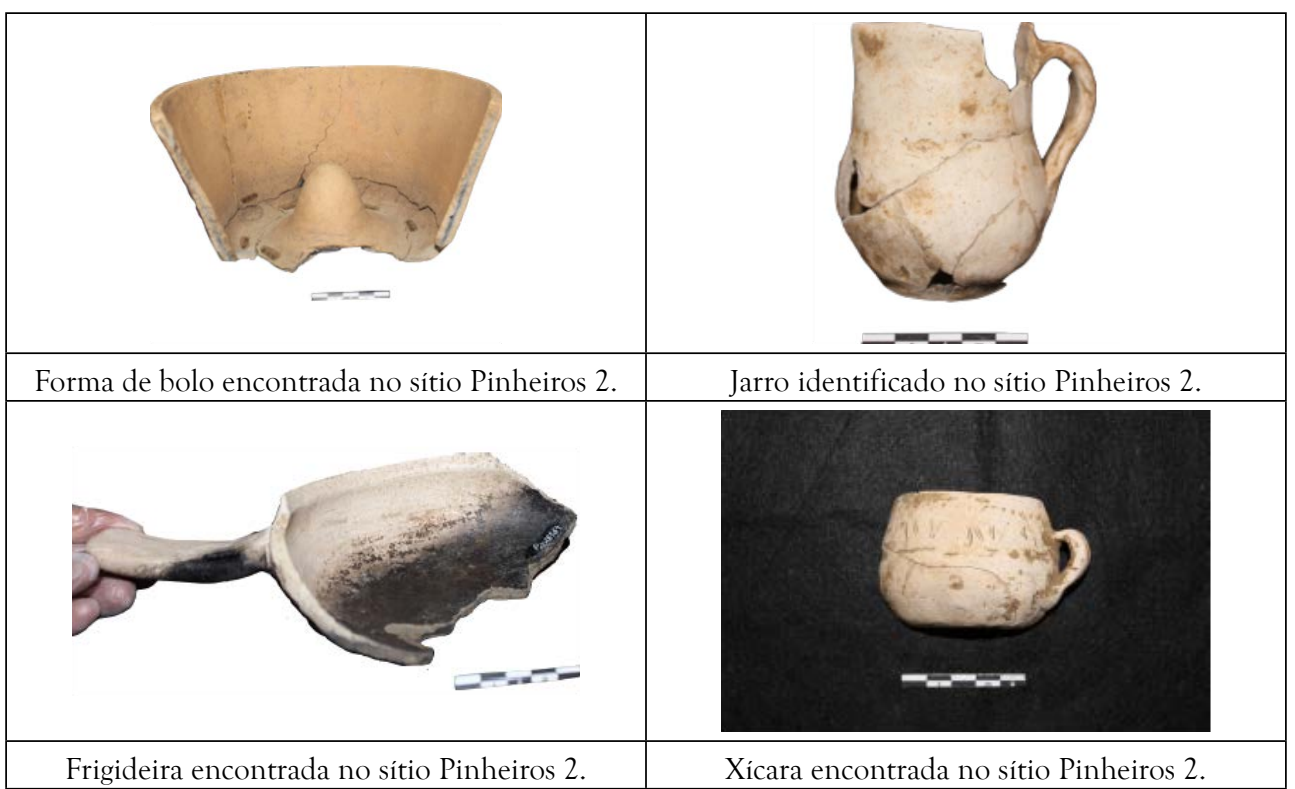

Fig. 10. Morfologias europeias.

Fonte: elaborado pelo autor. 
Em tempo, é importante destacar que essa produção cerâmica não é somente um conjunto de imitações de peças europeias e sim algo novo. Os artesãos devem ser vistos como agentes ativos em uma sociedade colonizada que, apesar de serem oprimidos e colocados para trabalhos forçados, sua produção e sua cultura encontraram uma forma de mudar o colonizador. Cerâmica tradicionalmente portuguesa é incomum, e quando encontrada, normalmente é em contextos de cidades mais intimamente ligadas ao comércio com Portugal, como é o caso de Salvador (Etchevarne 2006) e Rio de Janeiro (Calza et al. 2013), e o que se torna mais recorrente no registro arqueológico é essa combinação de práticas. Como esses motivos não desaparecem em períodos cronologicamente mais recentes, é possivel compreender que os portugueses também foram mudados nesse processo de colonização, especialmente quando se ocupa uma região com poucos recursos e que é majoritariamente ocupada por indígenas. Por exemplo, de acordo com Carrara (2014), na década de 1670 havia cerca de 12.000 pessoas vivendo na cidade de São Paulo, entretanto, apenas 1.500 eram consideradas brancas europeias de acordo com o censo da época.

Mudanças culturais nunca são um processo unilateral, com a cultura ancestral sendo deixada de lado por causa do colonizador (Arroyo 2016; Ortiz 1991; Sallum 2018; Wilson \& Rogers 1993). Os oprimidos também possuem agência, e lutam para manter seus valores tradicionais, promovendo assim, um processo cultural de mão dupla, em que opressores e oprimidos são transformados pela experiência colonial.

\section{Agradecimentos \\ Primeiramente gostaria de agradecer à todos os integrantes da VI Semana Internacional de Arqueologia que me permitiram apresentar este trabalho. Também agradecer à minha orientadora Profa. Dra ${ }^{a}$. Marisa Coutinho Afonso. E, por último, agradecer à CAPES (Código de Financiamento - n001), por todo o financiamento à minha pesquisa de mestrado.}

MANFRINI, M. Decorative variability in São Paulo's colonial ceramics: Influences and resistances. R. Museu Arq. Etn. 37: 178-203, 2021.

\begin{abstract}
Clay pots produced and distributed in the city of São Paulo during the first centuries of its foundation possessed a great variation of decorative motifs that explored a wide array of techniques, such as incisions, grooves, brushes, digits, and with appliqués. Such techniques can be related to styles that were previously seen in Indigenous and/or African traditions that were affected by European colonization. These decorative styles are frequently associated to morphologies that do not exist among these same traditions but are common in European productions such as teacups, jars, frying pans. Taking this into account, it is possible to observe a cultural amalgamation resulting from processes of domination and resistance. Archaeological studies on Culture Contact and Diaspora frequently associate the usage of certain decorative styles as forms of cultural resistance and persistence towards European colonial domination. In this fashion, we explore the decorative motifs identified in the archeological sites Pinheiros 2, Casa do Bandeirante, and Casa Bandeirista do Itaim Bibi and seek possible comparisons with Indigenous and African decorations that might indicate how power relations took place in São Paulo's society, and how cultural persistence can be observed in local pottery.
\end{abstract}

Keywords: Historical archaeology; Local/regional pottery; Decorations; Archaeology of São Paulo. 
Variabilidade decorativa na cerâmica paulista colonial: influências e resistências

R. Museu Arq. Etn., 37: 178-203, 2021.

\section{Referências bibliográficas}

Afonso dos Santos, A.M. 2016. A Casa do Bandeirante como espaço museológico (1954-1964). Dissertação de mestrado. Universidade de São Paulo, São Paulo.

Agnolin, A. 2007. Jesuítas e selvagens: a negociação da fé no encontro catequético-ritual americano-tupi (séculos XVI-XVII). Humanitas, São Paulo.

Agostini, C. 1998a. Padrões de decoração em vasilhames cerâmicos no Rio de Janeiro do século XIX. Revista de Arqueologia 11: 1-14.

Agostini, C. 1998b. Resistência cultural e reconstrução de identidades: um olhar sobre a cultura material dos escravos do século XIX. Revista de História Regional 3: 115-137.

Agostini, C. 2009. Cultura material e a experiência africana no sudeste oitocentista: cachimbos de escravos em imagens, histórias, estilos e listagens. Topoi 10: 39-47.

Agostini, C. 2010. Panelas e paneleiras de São Sebastião: um núcleo produtor e a dinâmica social e simbólica de sua produção nos séculos XIX e XX. Vestígios 4: 127-144.

Agostini, C. 2011. Mundo atlântico e clandestinidade: dinâmica material e simbólica em uma fazenda litorânea no sudeste, século XIX. Tese de doutorado. Universidade Federal Fluminense, Rio de Janeiro.

Albuquerque, P. 2001. A faiança portuguesa: demarcador cronológico na Arqueologia Brasileira. S.n., Recife.

Andreatta, M.D. 1986. Arqueologia histórica na cidade de São Paulo. Arqueologia 5: 113-115.

Arroyo, J. 2016. Transculturation, syncretism, and hybridity. In: Martínez-San Miguel, Y.; SifuentesJáuregui, B.; Balausteguigoitia, M. (Eds.). Critical Terms in Caribbean and Latin American Thought. New Directions in Latin American Cultures. Palgrave Macmillan, New York, 133-144.
Barros, L. et al. 2012. A olaria renascentista de Santo António da Charneca - Barreiro: a louça doméstica. Arqueologia Moderna: 361-372.

Blaj, I. 2002. A trama das tensões: o processo de mercantilização de São Paulo colonial (1681-1721). Humanitas/Fapesp, São Paulo.

Borrego, M.A. 2010. A teia mercantil: negócios e poderes em São Paulo colonial. Alameda; Fapesp, São Paulo.

Brochado, J.P. 1973. Contatos europeus e indígenas: um estudo de aculturação através das mudanças na cultura material. Revista do Instituto de Filosofia e Ciências Humanas 2: 11-47.

Calza, C. et al. 2013. Análise de peroleiras e cachimbos cerâmicos provenientes de escavações arqueológicas. Boletim Museu Paraense Emílio Goeldi Ciências Humanas 8: 621-638.

Campos, S. 2007. Bonecas Karajá: modelando inovações, transmitindo tradições. Tese de doutorado. Pontifícia Universidade Católica de São Paulo, São Paulo.

Cardoso, G.; Batalha, L. 2017. Evidências de produção oleira dos finais do século XVI a meados do século XVII no Largo de Jesus (Lisboa). In: Anais do I Encontro de Arqueologia de Lisboa: uma cidade em escavação, 2017, Lisboa, 147-181.

Carrara, A. 2014. A população do Brasil, 1570-1700: uma revisão historiográfica. Revista Tempo 20: 1-21.

Casimiro, T.; Barros, L. 2012. De quem são estas ollas? Comer, beber, armazenar em Almada no século XIII. In: Actas do X Congresso Internacional a Cerâmica Medieval no Mediterrâneo, 2012, Silves, 392-397.

Casimiro, T. et al. 2018. Ceramics and cultural change in medieval (14th-15th century) Portugal: The case of post-Reconquista Santarém. Medieval Ceramics 37: 21-36. 
David, N.; Sterner, J.; Gavua, K. 1988. Why pots are decorated. Current Anthropology 29: 365-389.

Dias Júnior, O. 1988. A cerâmica neobrasileira. Arqueo-IAB, TextosAvulsos 1: 3-13.

Erig Lima, L.F. 2012. A cerâmica Capão do Canga: uma nova indústria cerâmica na bacia do Alto Guaporé, Mato Grosso, Brasil. Amazônica 4: 186-220.

Etchevarne, C. 2006. Aspectos da cerâmica colonial do século XVII, em Salvador, Bahia. CLIO Arqueológica 1: 53-79.

Furtado, C. 2000. Formação econômica do Brasil. Publifolha, São Paulo.

Gaspar, M. 2014. A cerâmica arqueológica na terra indígena Kaiabi (MT/PA). Dissertação de mestrado. Universidade de São Paulo, São Paulo.

Hegmon, M. 1992. Archaeological research on style. Annual Review of Anthropology 21: 517-536.

Kashimoto, E.M.; Martins, G.R. 2019. Catálogo de artefatos cerâmicos arqueológicos de Mato Grosso do Sul. Instituto Histórico e Geográfico de Mato Grosso do Sul, Campo Grande.

Kayo, A. 2013. Onde passava o Rio Pinheiros. Disponível em: <https://bit.ly/30d1YDy $>$. Acesso em: 07/07/2018.

Kok, G. 2009. Peregrinações conflitos e identidades indígenas nas aldeias quinhentistas de São Paulo. In: Anais do XXV Simpósio Nacional de História, 2009, Fortaleza.

Lemos, C. 2008. Índios e negros. In: A Divina Inspiração Sagrada e Religiosa - Sincretismos. Catálogo da exposição. Imprensa Oficial do Estado de São Paulo, Museu Afro Brasil, São Paulo.

Machado, N.; Schneider, P.; Schneider, F. 2008. Análise parcial sobre a cerâmica arqueológica do Vale do Taquari, Rio Grande do Sul. Cerâmica 54: 103-109.
Magalhães, W. 2015. Estudo arqueométrico dos sítios arqueológicos Inhazinha e Rodrigues Furtado, município de Perdizes/MG: da argila à cerâmica... possíveis conexões entre os vasilhames cerâmicos e as fontes argilosas. Dissertação de mestrado. Universidade de São Paulo, São Paulo.

Mayumi, L. 2008. Taipa, canela-preta e concreto. Estudo sobre o restauro de casas bandeiristas. Romano Guerra, São Paulo.

Monteiro, J. 1995. Negros da Terra: índios e bandeirantes nas origens de São Paulo. Companhia das Letras, São Paulo.

Moreira, M. 2019. Projeto Quebra-Anzol, Minas Gerais: estudo de continuidade e mudança tecnológica intersítios na cultura material cerâmica. Dissertação de mestrado. Universidade de São Paulo, São Paulo.

Mrozowski, S.; Gould, D.; Pezzarossi, H. 2015. Indigenous innovation and colonial inevitability. In: Cipolla, C.N.; Haynes, K.H. (Eds.). Rethinking colonialism: comparative archaeological approaches. University Press of Florida, Gainesville, 121-142.

Munsberg, S. 2018. Dos seiscentos aos oitocentos: estudo da variabilidade estilística da cerâmica durante os processos de construção e reconfiguração das identidades paulistanas. Dissertação de mestrado. Universidade Federal de Minas Gerais, Belo Horizonte.

Neoépica Arqueologia. 2017. Os silos do Palácio de Santa Helena: Lisboa. In: Arnaud, J.M.; Martins, A. (Eds.). Arqueologia em Portugal - Estado da Questão. AAP, Lisboa, 1751-1766.

Orser, C. 1999. A teoria de rede e a arqueologia da história moderna. Revista do Museu de Arqueologia e Etnologia 3: 87-101.

Ortiz, F. 1991. Contrapunteo cubano del tabaco y el azúcar. Editorial Ciencias Sociales, La Habana. 
Pacce, M. 1980. A propósito da Casa do Bandeirante. Revista do Arquivo Municipal de São Paulo 43: 7-50.

Petrone, P. 1995. Aldeamentos Paulistas. Edusp, São Paulo.

Prado Júnior, C. 1969. História econômica do Brasil. Editora Brasiliense, São Paulo.

Reis Filho, N. 2004. São Paulo: vila, cidade, metrópole. Prefeitura do Município de São Paulo; BankBoston, São Paulo.

Ribeiro, L.; Jácome, C. 2014. Tupi ou não Tupi? Predação material, ação coletiva e colonialismo no Espírito Santo, Brasil. Boletim do Museu Paraense Emílio Goeldi 9(2): 465-486.

Sallum, M. 2018. Colonialismo e ocupação tupiniquim no litoral sul de São Paulo: uma história de persistência e prática cerâmica. Tese de doutorado. Universidade de São Paulo, São Paulo.

Souza, M.A.T. 2013. Por uma arqueologia da criatividade: estratégias e significações da cultura material utilizada pelos escravos no Brasil. In: Agostini, C. (Org.). Objetos da escravidão: abordagens sobre a cultura material da escravidão e seu legado. 7Letras, Rio de Janeiro, 11-36.

Souza, M.A.; Agostini, C. 2012. Body marks, pots, and pipes: some correlations between African scarifications and pottery decoration in eighteenth and nineteenth century Brazil. Historical Archaeology 46: 102-123.

Souza, R.A. 2013. Arqueologia na terra da garoa: leituras arqueológicas da grande São Paulo. Revista de Arqueologia Americana 31: 289-325.

Symanski, L.C. 2010. Cerâmicas, identidades escravas e crioulização nos engenhos de Chapada dos Guimarães (MT). História Unisinos 14: 293-310.

Taunay, A. 2004. História da cidade de São Paulo. Edições do Senado Federal, Brasília.
Tocchetto, F. 1996a. A cerâmica do guarani missioneiro como símbolo de identidade étnica. Historical Archaeology in Latin America 13: 77-98.

Tocchetto, F. 1996b. Possibilidades de interpretação do conteúdo simbólico da arte gráfica Guarani. Revista do Museu de Arqueologia e Etnologia 6: 22-45.

Vilardaga, J. 2011. São Paulo na órbita do império dos Felipes: conexões castelhanas de uma vila da América Portuguesa durante a União Ibérica (1580-1640). Tese de doutorado. Universidade de São Paulo, São Paulo.

Vilardaga, J. 2017. Na bagagem dos peruleros: mercadoria de contrabando e o caminho proibido de São Paulo ao Paraguai na primeira metade do século XVII. Anais do Museu Paulista 25: 127147.

Wilson, S.; Rogers, J.D. 1993. Historical dynamics in the contact era. In: Wilson, S.; Rogers, J.D. (Eds.). Ethnohistory and archaeology: approaches to postcontact change in the Americas. Springer, New York, 3-15.

Zanettini Arqueologia. 2009. Programa de salvamento arqueológico do Sítio Casa Bandeirista do Itaim Bibi, município de São Paulo, SP e laudo pericial definitivo, autorização federal de pesquisa. Relatório Final, São Paulo.

Zanettini Arqueologia. 2011a. Programa de prospecção arqueológica, terreno sito à Rua Butantã, $n^{\circ} 298$, Bairro de Pinheiros - Sítio Arqueológico Pinheiros 2. Relatório final, São Paulo.

Zanettini Arqueologia. 2011b. Programa de resgate e monitoramento arqueológico do Sítio Casa Bandeirista do Itaim Bibi, município de São Paulo - SP. Relatório final, São Paulo.

Zanettini Arqueologia. 2012. Programa de prospecção e resgate arqueológico, terreno sito à Rua Butantã, $n^{\circ}$ 298, Bairro de Pinheiros - Sítio Arqueológico Pinheiros 2. Relatório final, São Paulo. 
Zanettini Arqueologia. 2013. Programa de resgate arqueológico, Sítio Arqueológico Pinheiros 2, Rua Butantã, $n^{\circ}$ 298, Bairro de Pinheiros.

Relatório final de monitoramento, São Paulo.

Zanettini, P. 2005. Maloqueiros e seus palácios de barro: o cotidiano doméstico na casa bandeirista.
Tese de doutorado. Universidade de São Paulo, São Paulo.

Zuse, S. 2009. Os Guarani e a Redução Jesuítica: tradição e mudança técnica na cadeiaoperatória de confecção dos artefatos cerâmicos do sítio Pedra Grande e entorno. Dissertação de mestrado. Universidade de São Paulo, São Paulo. 